\title{
Les protéines du lait à activité enzymatique et hormonale
}

\author{
par \\ B. BLANC*
}

\section{Rés u mé}

Les enzymes et les protéohormones ne représentent qu'une minorité des protéines du lait. Leur activité et leur répartition ne manquent cependant pas d'intérêt.

Les laits des mammifères renferment différentes enzymes. On en dénombre plus de 60 qui ont pu être isolées ou dont l'activité a été déterminée. La moitié d'entre elles sont des hydrolases. Les enzymes du lait proviennent d'organes, du sang et surtout des cellules sécrétrices de la glande mammaire où elles sont, en partie, liées à des membranes. Des cellules somatiques et des micro-organismes participent également à certaines activités enzymatiques. Les enzymes du lait se rencontrent aussi bien dans le lait maigre que dans la crème, parfois liées à la caséine ou à la membrane des globules gras. L'activité enzymatique du lait est influencée par différents facteurs tels que période de lactation, saison, espèce de mammifère, race, alimentation, état de santé de la mamelle. Les enzymes peuvent jouer un rôle d'indicateurs pour certains procédés technologiques. Dans l'alimentation du nouveau-né, elles sont essentielles pour leurs effets digestifs et antibactériens.

La glande mammaire est l'organe récepteur pour les hormones dont la présence dans le lait est le résultat de l'équilibre physiologique entre leur concentration dans le sang, le liquide extra-cellulaire, les cellules épithéliales de la glande mammaire et le lait sécrété. Outre les hormones stéroïdes et les prostaglandines, le lait contient des protéohormones et des hormones peptidiques, détectables dans le domaine du $\mathrm{ng} / \mathrm{ml}$ au moyen de micro-méthodes. La prolactine, qui est active pendant la lactogenèse et la lactation, est l'hormone du

* Station fédérale de recherches laitières - CH-3097 Liebefeld-Berne (Suisse). (Direction : B. Blanc). 
lait qui suscite le plus d'intérêt. Vu les faibles quantités présentes dans le lait de vache, les protéohormones ne constituent aucun risque pour le consommateur. Dans la biologie du nouveau-né, la prolactine semble assumer une fonction physiologique.

\section{S u $\mathrm{m}$ mary}

Enzymes and protein hormones represent only a small part of total milk proteins. However, their activities and distribution are of interest.

More than 60 enzymes have been detected in and isolated from milk, and their activities have been determined. About half of them are hydrolases. The milk enzymes come from organs, blood and particularly the secretory mammary gland cells, where they are partially bound to the membranes. Somatic cells and microorganisms also contribute certain enzymic activities. The milk enzymes occur both in skim milk and cream, where they may be bound either to casein or to the fat globule membrane. The enzymic activities of milk are influenced by different factors, such as stage of lactation, season, species, race, food, mastitis. The milk enzymes play a role as indicators for certain technological changes. They are also essential for the nutrition of neonates because of their digestive and antibacterial effects.

The mammary gland is the target organ of milk hormones. Their presence in milk is the result of the physiological equilibria between their concentration in blood, extra-cellular fluid, mammary epithelial cells and secreted milk. Milk contains steroid hormones and prostaglandins as well as protein and peptide hormones, which can be detected by micromethods $(\mathrm{ng} / \mathrm{ml})$. Prolactin, which is active during lactogenesis and lactation, is the milk hormone that has given most attention. Due to their low concentrations in bovine milk, these protein hormones do not involve any health hazard for the consumer. Prolactin seems to have a physiological function in the biology of neonates.

\section{INTRODUCTION}

Le lait des mammifères renferme différentes protéines, de nature caséinique ou lactosérique principalement. Dans le lait de vache, les caséines $(\alpha, \beta, K, \gamma)$ représentent $80 \%$, suivies des protéines lactosériques ( $\alpha$-lactalbumine, $\beta$-lactoglobuline, sérum-albumine, immunoglobulines) et la fraction de protéoses-peptones (Alais et Blanc, 1975 ; Brunner, 1981). Dans le lait de femme, les protéines lactosériques sont les plus importantes, représentant les $70 \%$ de l'ensemble (Blanc, 1981). D'autres protéines du lait sont les enzymes et les protéo- 
hormones qui ne représentent qu'une infime partie de l'ensemble protéique. Leur présence, leurs proportions, leurs activités et leur répartition ne manquent cependant pas d'intérêt. Les laits de femme, de vache et d'autres animaux contiennent un grand nombre d'enzymes provenant des organes, du sang ou des cellules de la glande mammaire. Les enzymes peuvent également être des produits de microorganismes ou de cellules somatiques. Dans le lait, on les rencontre dans la phase aqueuse, sous forme soluble ou liées aux caséines, et dans la phase lipidique, au sein de la membrane des globules gras. L'activité des enzymes est influencée par la période de lactation, la saison, l'espèce de mammifère, la race, l'alimentation et la santé mammaire. Leur importance peut être envisagée d'un point de vue technologique ou nutritionnel. Parmi les protéohormones, la prolactine et les divers facteurs qui l'influencent sont au centre de l'intérêt.

\section{ENZYMES}

\section{Inventaire des enzymes du lait}

Dans des conditions normales, les laits contiennent une grande variété d'enzymes. Il y a 100 ans, on mentionna pour la première fois la présence de la lactoperoxydase, probablement la première enzyme découverte dans le lait de vache (Arnold, 1881). Depuis on a mis en évidence, purifié, isolé ou caractérisé toute une série d'autres enzymes. Divers articles traitent d'enzymes particulières (Bray, 1975 ; Chilliard, 1982 ; Hill et Brew, 1975 ; Humbert et Alais, 1979 ; Jensen et Pitas, 1976) et d'autres sur l'ensemble des enzymes du lait (Alais et Blanc, 1975 ; Fox et Morrissey, 1981 ; Got ,1971 ; Groves, 1971 ; Jenness, 1974 ; Shahani, 1966; Shahani et al., 1973 ; Shahani et al., 1980 ; Tkadlecova et Hanus, 1973). Les indications des différents auteurs sur le nombre d'enzymes constatées dans le lait ne concordent pas exactement. Got (1971) a dénombré 55 à 60 enzymes, dont 9 sont traitées en détail ; Groves (1971) en cite environ 25 et Jenness (1974) réunit plus de 40 enzymes rencontrées dans le lait de vache et de femme. Shahani et al. (1973) décrivent 21 enzymes en détail et donnent des références bibliographiques pour 21 autres. D'après Fox et Morrissey (1981), le lait bovin renferme quelque 30 enzymes. Ces auteurs décrivent l'isolement, la caractérisation et le rôle des 10 enzymes les plus importantes, soit la catalase, la protéinase, le lysozyme, la xanthine-oxydase, la sulfhydryloxydase, la peroxyde-dismutase, la lactoperoxydase, les phosphomonoestérases (phosphatases) alcaline et acide ainsi que les lipases et les estérases. Une revue sur la présence d'enzymes dans le lait maternel a été publiée par Shahani et al. (1980).

Dans le tableau 1, nous énumérons les enzymes découvertes jusqu'à présent dans les laits de vache et de femme et d'autres mammifères d'après la classification de l'Union internationale de biochimie 
(UIB). Cette nomenclature subdivise les enzymes en six classes principales, d'après la réaction chimique qu'elles catalysent :

1. Les oxydo-réductases sont des enzymes qui transfèrent des électrons ou de l'hydrogène et qui catalysent des processus d'oxydoréduction.

2. Les transférases transfèrent des groupes fonctionnels.

3. Les hydrolases scindent les liaisons ester, glycosidiques, peptidiques et autres liaisons $\mathrm{C}-\mathrm{N}$ ainsi que les anhydrides d'acides.

4. Les lyases catalysent des réactions de décomposition en formant des doubles liaisons ou en ajoutant des groupes à des doubles liaisons.

5. Les isomérases catalysent des changements géométriques ou structuraux au sein d'une molécule.

6. Les ligases catalysent l'association de 2 molécules du substrat en utilisant l'ATP.

Dans le lait, on rencontre les enzymes de toutes les classes principales, à l'exception des ligases qui, à notre connaissance, n'ont pu y être décelées (tab. 1). Il faut souligner que les enzymes détectées dans les laits de vache et de femme se recrutent, en majeure partie, parmi les oxydo-réductases, les transférases et les hydrolases. Quant aux laits d'autres mammifères, l'information sur la présence d'enzymes fait encore largement défaut.

Il est possible que quelques-unes des enzymes mentionnées soient identiques. Ainsi, la $\gamma$-glutamyl-transpeptidase (Majunder et Ganguli, 1972 a, b) et la $\gamma$-glutamyl-transférase (Yasumoto et al., 1978) sont probablement une seule et même enzyme, qui catalyse le transfert de restes radicaux $\gamma$-glutamyles à partir de glutathion sur une multitude d'accepteurs. D'après Iwami et al. (1981), les activités catalytiques de l'o-glutamyl-transférase et de la glutathion-oxydase, étroitement associées dans les membranes du lait écrémé, s'exerceraient en deux sites actifs distincts d'une seule enzyme, composée de deux sousunités non identiques. Sliwkowski et al. (1981) concluent que les activités de la sulfhydryl-oxydase et de la $\gamma$-glutamyl-transférase sont distinctes et séparables.

Quand on tient compte de sa composition et de ses propriétés catalytiques, la sulfhydryl-oxydase doit être considérée, d'après Janolino et Swaisgood (1975) comme différente de la xanthine-oxydase (EC 1.2.3.2.) et de la thiol-oxydase (EC 1.8.3.2.). La littérature ne précise pas si cette dernière enzyme est présente dans le lait. La thiol-oxydase indiquée dans les revues de Got (1971), Jenness (1974) et Shahani et al. (1973) est identique à la sulfhydryl-oxydase décrite par Kiermeier et Petz (1967). Selon Anderson et Cawston (1975), c'est la protéine disulfure-isomérase (EC 5.3.4.1.).

Associée à l'a-lactabulmine, l'UDP-galactose N-acétyl-glucosamine galactosyl-transférase forme comme protéine A la lactose-synthétase 


\section{TABLEAU 1 - TABLE 1}

Liste des enzymes mises en évidence dans le lait (d'après Fox et MORRISSEY, 1981 ; GOT, 1971 ; JENNESS, 1974 ; SHAHANI et al., 1980 et d'autres auteurs)

Enzymes present in milk

(from Fox and MORRISSEY, 1981 ; GoT, 1971 ; JENNESS, 1974 ;

SHAHANI et al., 1980 and from other authors)

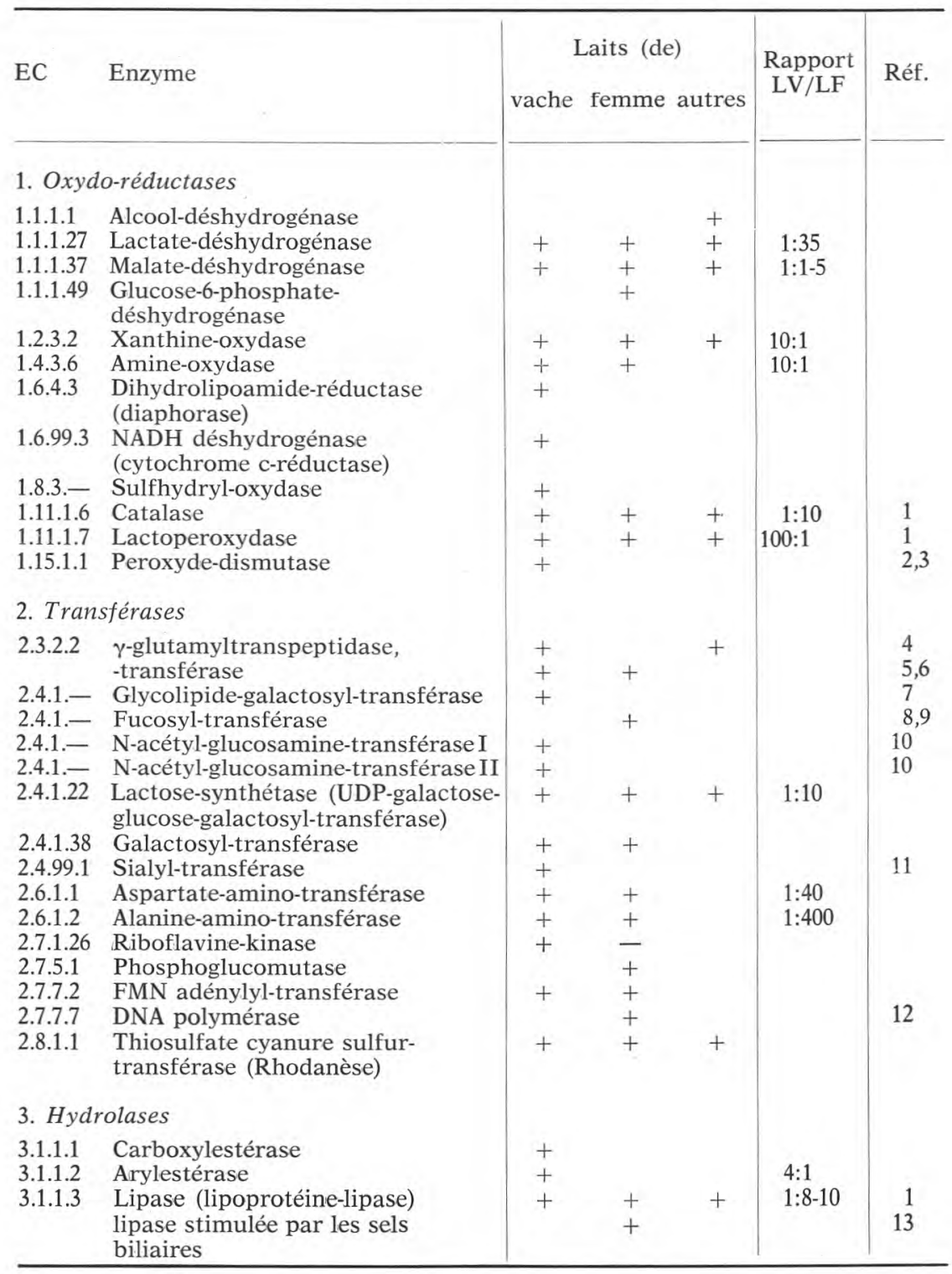




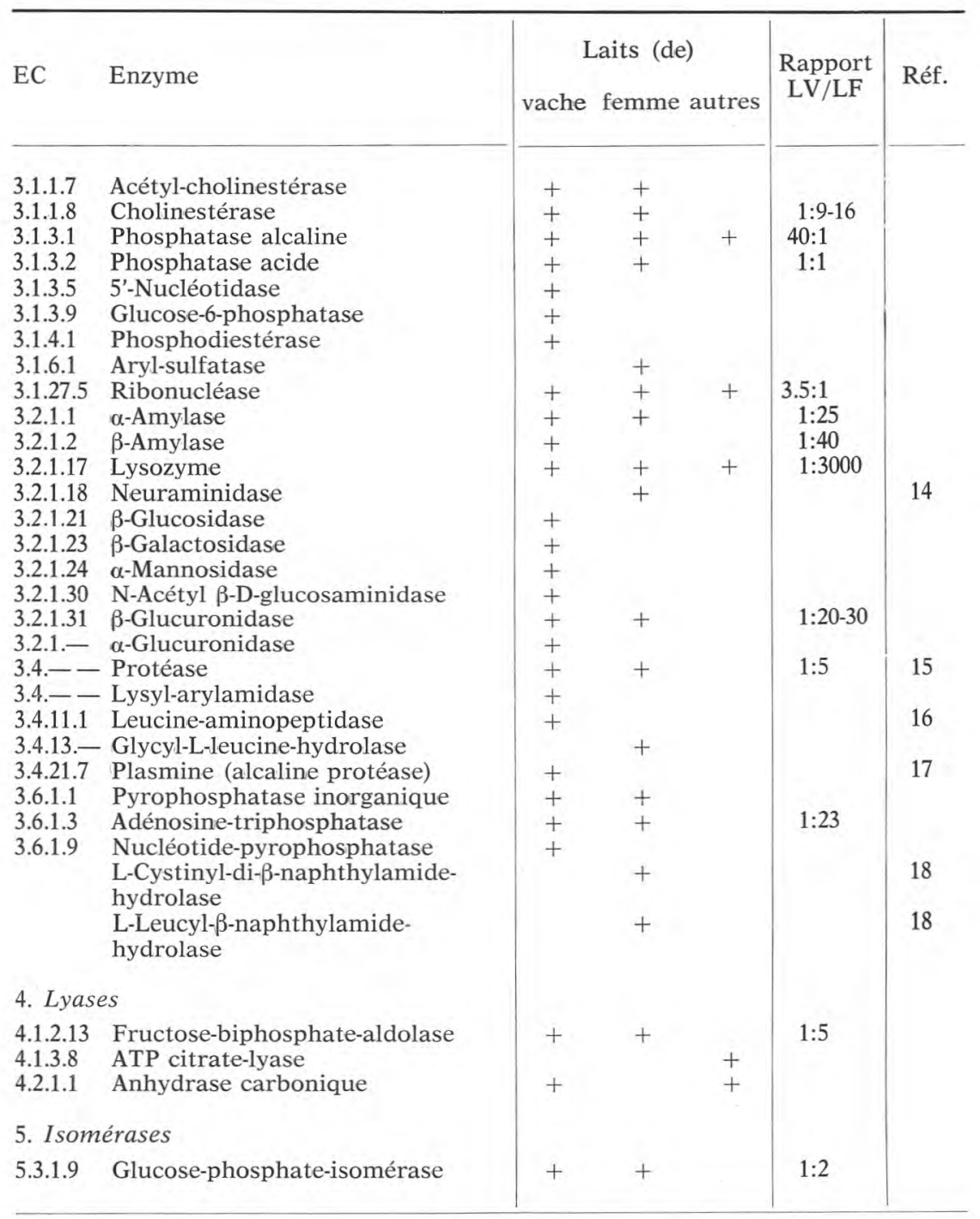

\section{Références}

1. Sharma et Ganguli, 1971.

2. HILL, 1975.

3. HICKs et al., 1975.

4. MAJUMder et Ganguli, 1972 a.

5. LANDON, 1975.

6. YаSUMOTo et al., 1978.

7. Bushway et KeEnan, 1979.

8. VANDENBROUCKE et al. ,1976.

9. Clamagiraud-Mulet et al., 1981.
10. Harpaz et Schachter, 1980.

11. PAULSON et al., 1977.

12. KANTOR et al., 1979.

13. Hernell et Olivecrona, 1974 b.

14. SCHAUER et al., 1976.

15. Kaminogawa et Yamauchi, 1972.

16. EICHEL, 1981.

17. Kaminogawa et al., 1972.

18. BROUET-YAGER, 1974.

N.B. : Les numéros EC ont été adaptés à la nomenclature des enzymes de 1978 (Academic Press, New York, 1979). 
et catalyse le processus terminal de la biosynthèse du lactose (Hill et Brew, 1975). On ne sait pas encore si la glycolipide-galactosyltransférase et la sous-unité catalytique de la lactose-synthétase sont identiques ou s'il s'agit de deux enzymes différentes (Bushway et Keenan, 1979).

\section{Provenance des enzymes}

Les enzymes du lait proviennent de différentes sources. Elles peuvent être tranférées d'organes dans le sang, où elles sont déjà présentes et d'où elles sont transportées à la glande mammaire. Dans les cellules sécrétrices, les enzymes cytoplasmiques se trouvent liées aux membranes. Pendant la sécrétion lactée, les enzymes sont sécrétées non seulement de la cellule, mais encore du sang.

Certaines enzymes du lait peuvent également être attribuées à l'activité biosynthétique et à la lyse des micro-organismes, qui, par contamination interne dans le canal du pis ou par contamination externe après prélèvement du lait, l'ont souillé.

Parmi les différents groupes de micro-organismes présents dans le lait cru : bactéries pathogènes, levures, moisissures, microcoques thermolabiles, bactéries corynéformes et bactéries lactiques, il y a des bactéries gram-négatives ainsi que des bactéries gram-positives thermorésistantes (Stadhouders, 1975). Ces dernières détériorent le lait ayant subi des traitements thermiques, moins par l'intervention d'enzymes spécifiques que par leur croissance. Quelques groupes de bactéries gram-négatives, principalement de la famille des Pseudomonas, produisent des enzymes extracellulaires thermostables telles que protéinases et lipases (Law, 1979). La présence de tels microorganismes dans le lait, sensibles à la chaleur, mais se multipliant dans des conditions psychrotrophes et formant des enzymes extracellulaires pose des problèmes de plus en plus importants pour l'économie laitière ; un de ces problèmes est la nécessité d'une réfrigération prolongée du lait à la ferme.

Une dernière source d'enzymes est due à la présence d'un nombre variable (normalement $100000 / \mathrm{ml}$ ) parfois excessif de cellules somatiques, des leucocytes en particulier. Elles constituent une source supplémentaire d'enzymes, qui est d'autant plus importante que les conditions de manipulation du lait favorisent la lyse cellulaire. Des nombres de cellules fort accrus peuvent affecter, à différents degrés, les activités enzymatiques. Ce point sera discuté dans le chapitre sur l'influence des mammites.

L'activité de la lactate-déshydrogénase ( $\mathrm{LDH}$ ) et la répartition en pour cent des isoenzymes LDH peuvent servir d'exemples pour démontrer l'importance des leucocytes comme producteurs d'enzymes (tab. 2). Dans du lait normal, on ne trouve que les deux isoenzymes $\mathrm{LDH}_{1}$ et $\mathrm{LDH}_{2}$, et l'activité est plus de 10 fois plus basse que dans le lait de mammite (Bogin et Ziv, 1973). Les répartitions en pour cent 
des isoenzymes LDH dans le lait de mammite et dans les leucocytes sont très semblables (Bogin et al., 1977). Que l'augmentation de l'activité $\mathrm{LDH}$ dans le lait malade soit imputable non seulement aux leucocytes, mais aussi aux cellules épithéliales et interstitielles de la mamelle malade peut être déduit de la répartition en pour cent des isoenzymes dans des tissus mammaires normal et atteint de mammite (Bogin et al., 1976; Bogin et al., 1977). Cependant, ces résultats ne montrent pas dans quelle mesure les leucocytes normalement présents dans le lait participent aux activités enzymatiques.

Dans les paragraphes suivants, nous traiterons plus en détail la provenance des enzymes de l'organisme.

a) De multiples réactions chimiques se déroulent dans l'organisme sous l'action d'enzymes. La présence ou l'absence d'enzymes dans les cellules dépend de l'intensité de l'activité métabolique de chaque organe, qui est variable.

La présence de certaines enzymes semblables dans différents organes et dans le lait peut sans doute s'expliquer par le fait qu'elles ont été transportées par voie sanguine de l'organe en question à la glande mammaire. Dans les glandes bovines sublinguale, submaxillaire et parotide, par exemple, Morrisson et Allen (1963) et Morrisson et al. (1965), ont trouvé une protéine immunologiquement identique à la lactoperoxydase. Les résultats de mesures physico-chimiques démontrent l'identité de l'enzyme purifiée de la glande submaxillaire et de la lactoperoxydase. De même, la plasmine et le plasminogène du sang bovin ainsi que la protéinase alcaline du lait de la même vache coïncident largement, comme le révèlent des mesures cinétiques et des analyses des conditions d'inhibition spécifiques (Reimerdes et al., 1981 a, b). Quant à la peroxyde-dismutase, on rapporte qu'elle est identique à l'enzyme des érythrocytes bovins (Hill, 1975).

Des études immunochimiques électrophorétiques ainsi que des études sur l'inhibition et les activités spécifiques mettent en évidence l'identité de la lipase du lait maternel, stimulée par les sels biliaires et de la carboxylester-hydrolase du suc pancréatique (Bläckberg et al., 1981).

b) Les composants majeurs du lait se constituent lors de la sécrétion du lait dans la glande mammaire à partir de métabolites simples (glucose, acétate, $\beta$-hydroxybutyrate, acides aminés, acides gras) apportés par le sang. Dans les compartiments du cytoplasme de la cellule, ces substances sont transformées par les réactions chimiques les plus différentes, catalysées par de nombreuses enzymes, soit le métabolisme du glucose, la synthèse du lactose, le métabolisme lipidique, la synthèse de la matière grasse du lait, le métabolisme des acides aminés et la synthèse des protéines.

Les vésicules sécrétoires, qui se détachent de l'appareil de Golgi, libèrent le lactosérum de la cellule sécrétrice dans la lumière de l'alvéole, tandis que la membrane de la vésicule se fond avec celle 


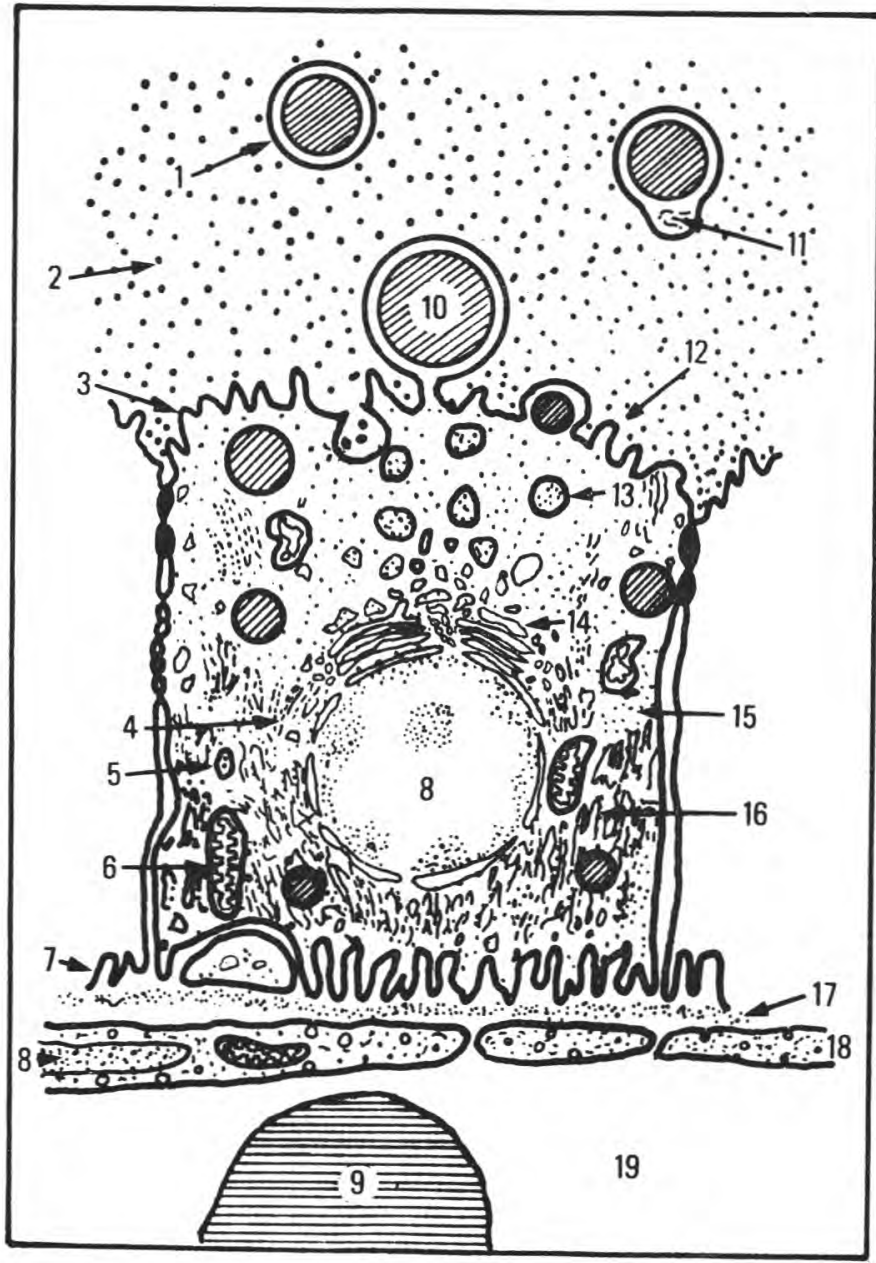

fig. 1

Représentation schématique d'une cellule épithéliale de la glande mammaire.

Diagram of an epithelial cell of the mammary gland.

1. Membrane du globule gras.

2. Protéine.

3. Membrane plasmique apicale.

4. Réticulum endoplasmique lisse.

5. Lysosome.

6. Mitochondrie.

7. Membrane basale cellulaire

8. Noyau.

9. Globule rouge.

10. Graisse.
11. Fragment cytoplasmique.

12. Microvillosités.

13. Granules de sécrétion.

14. Appareil de Golgi.

15. Ribosomes libres.

16. Réticulum endoplasmique granulaire.

17. Membrane basale.

18. Paroi d'un capillaire sanguin.

19. Plasma sanguin. 


\section{$T A B L E A U 2$ - TABLE 2}

Activité de la lactate-déshydrogénase (LDH) et répartition en \% des isoenzymes dans les laits normal et de manimite, dans les leucocytes et dans les tissus mammaines normal et atteint de mammite

Lactate-dehydrogenase activity and distribution of isoenzymes (in \%) in regular and mastitic milks, in leukocytes and in mammary tissues from healthy and mastitis-infected cows

\section{Lait \\ normal \\ de mammite}

\section{Leucocytes}

Tissu mammaire

normal

atteint de mammite aiguë

\begin{tabular}{|c|c|c|c|c|c|}
\hline \multirow{2}{*}{$\begin{array}{c}\text { Activité } \\
\text { enzymatique } \\
\mathrm{mU} / \mathrm{ml}\end{array}$} & \multicolumn{5}{|c|}{ Répartition en \% } \\
\hline & $\mathrm{LDH}_{1}$ & $\mathrm{LDH}_{2}$ & $\mathrm{LDH}_{3}$ & $\mathrm{LDH}_{4}$ & $\mathrm{LDH}_{5}$ \\
\hline $277 \pm 152$ & 93,5 & 6,5 & $\overline{1}$ & - & - \\
\hline $4540 \pm 1210$ & 34,8 & 22,3 & 16,7 & 15,4 & 7,32 \\
\hline - & 36,4 & 26,1 & 15,8 & 12,4 & 2,13 \\
\hline $296 \pm 109$ & 70,9 & 11,25 & 7,8 & 6,27 & 2,29 \\
\hline $354 \pm 71$ & 26,2 & 21,04 & 18,4 & 22,19 & 11,03 \\
\hline
\end{tabular}

Références : BoGIN et ZIV, 1973 ; BoGIN et al., 1976, 1977.

du plasma dans la zone apicale (Keenan et al., 1974). C'est ainsi que les enzymes du cytosol parviennent au lait (voir fig. 1).

c) Dans la cellule sécrétrice (fig. 1), les globules gras du lait se déplacent progressivement vers la zone apicale. Immédiatement après la sécrétion par la cellule alvéolaire, ils sont entourés d'une membrane externe provenant du plasmalemme ou de la membrane golgienne et pourvus d'une couche intérieure entourant le noyau lipidique. Comme un flux constant de membranes s'écoule du réticulum endoplasmique à la membrane du plasma en passant par l'appareil de Golgi, on trouve dans les globules gras du lait des enzymes cytoplasmiques et lysosomiales (Anderson et Cawston, 1975 ; Kitchen, 1974 ; Patton et Keenan, 1975).

Le tableau 3 renseigne sur la répartition des enzymes à l'intérieur des cellules de la glande mammaire.

\section{Répartition des enzymes dans le lait}

Du fait que les vésicules golgiennes interviennent (directement) dans la formation des globules gras du lait, il est difficile d'expliquer la répartition de certaines enzymes entre lait maigre et crème. Si la plupart des activités enzymatiques de la membrane des globules 
TABLEAU $3-T A B L E 3$

Distribution des enzymes dans la cellule mammaire

Enzymes distribution in the mammary cell

Réticulum endoplasmique

Acétyl-cholinestérase**

Glucose-6-phosphatase**

NADH déshydrogénase

Sulfhydryl-oxydase*

Xanthine-oxydase*

\section{Cytoplasme}

Aspartate-amino-transférase** Anhydrase carbonique ${ }^{\star *}$

Catalase**

Aldolase*

Lactate-déshydrogénase ${ }^{* *}$

(Malate-déshydrogénase)

\section{Lysosomes}

$\mathrm{N}$-acétyl $\beta$-glucosaminidase

Phosphatase acide*

Catalase

$\beta$-Galactosidase

$\beta$-Glucuronidase

Lipase**

Ribonucléase I
Mitochondries

Cytochrome c-oxydase**

Succinate-déshydrogénase ${ }^{* *}$

Golgi

Sialyltransférase**

Glycoprotéine $\beta$-galactosyl-

transférase**

Lactose-synthétase**

(Thiamine-pyrophosphatase)

UDP galactose-glycosylcéramide

galactosyltransférase

\section{Plasmalemme}

Adénosine-triphosphatase*

Phosphatase alcaline*

$\gamma$-Glutamyltransférase*

Pyrophosphatase inorganique*

5'-Nucléotidase*

Nucléotide-pyrophosphatase*

Phosphodiestérase $\mathrm{I}^{*}$

UDP glycosylhydrolase*

* Activité des enzymes les plus importantes de la membrane des globules gras (d'après PatTon et KeEnan, 1975).

** Absentes de la membrane des globules gras (d'après ANDERson et CAwSTON, 1975).

() Inconnues dans la membrane des globules gras.

gras proviennent d'enzymes originaires du plasmalemme, on sait que quelques enzymes provenant d'autres compartiments de la glande mammaire sont présentes dans la membrane du globule gras (tab. 3).

La galactosyl-transférase se trouve tout d'abord dans l'appareil de Golgi (Keenan, 1974 ; Keenan et Huang, 1972) et, d'après la théorie du flux des membranes de Keenan et al. (1974), elle devrait donc se rencontrer après la sécrétion lactée dans la membrane des globules gras. Dans le lait, on la trouve cependant sous forme soluble avec des poids moléculaires divers, mais inférieurs à ceux de la galactosyl-transférase liée à la membrane (Magée et al., 1974). La plasmine exogène est capable de provoquer le fractionnement de la galactosyl-transférase (Magée et al., 1976).

Une analyse plus précise de la présence d'enzymes dans différentes fractions du lait montre une répartition inégale des enzymes 
entre lait maigre et crème (tab. 4). Parmi les enzymes indiquées, la $\mathrm{N}$-acétyl- $\beta$-D-glucosaminidase et la ribonucléase se trouvent avant tout dans le lait écrémé (Kitchen et al., 1970, 1978). Des activités enzymatiques diverses peuvent être associées, sous forme de complexes dus aux interactions protéine-protéine, tant à la membrane des globules gras qu'à la caséine. La protéase alcaline, par exemple, présente une activité protéolytique comparable à celle de la caséine sur une base protéique équivalente.

Cette protéase a été identifiée comme plasmine. Le mécanisme par lequel la plasmine et d'autres protéases se lient à la membrane pendant la synthèse du lait, pendant le séjour du lait dans la lumière de l'alvéole ou pendant la formation des globules gras, n'est pas encore élucidé. Cette lacune provient surtout du fait que la plasmine est une enzyme d'origine sanguine (Hofmann et al., 1979 ; Reimerdes et al., 1981 a, b). Parmi les enzymes liées à la caséine, la plus importante est la lipase. Plus de $70 \%$ en sont associés aux micelles, quelque $20 \%$ sont présents dans le lactosérum sous forme d'un complexe soluble enzyme-caséine et une petite partie se trouve dans la crème

\section{TABLEAU 4 - TABLE 4}

Distribution des activités enzymatiques dans des fractions du lait bovin (en \%)

Distribution of enzymic activities in bovine milk fractions (in \%)

\begin{tabular}{|c|c|c|c|c|c|c|c|c|}
\hline \multirow[b]{2}{*}{ Lait entier } & \multirow{2}{*}{$\begin{array}{c}\text { NAG } \\
100\end{array}$} & \multicolumn{2}{|c|}{ GGT } & \multirow{2}{*}{$\begin{array}{l}\text { Lip } \\
100\end{array}$} & \multicolumn{2}{|c|}{ Xo } & \multirow{2}{*}{$\begin{array}{l}\text { Cat } \\
100\end{array}$} & \multirow{2}{*}{$\begin{array}{r}\text { Rib } \\
100\end{array}$} \\
\hline & & 100 & 100 & & 100 & 100 & & \\
\hline Lait maigre & 91 & 75 & & & 15 & 54 & 73 & 106 \\
\hline Caséine & 7 & 18 & 25 & 75 & & 3 & 8 & 26 \\
\hline Lactosérum & 82 & 54 & & & & & & \\
\hline Crème & & 23 & 47 & 6 & 85 & 21 & 24 & 3 \\
\hline Globule gras & 2 & 7 & & & & & & \\
\hline Babeurre & & 18 & & & & 14 & 25 & 2 \\
\hline Références & 1 & 2 & 3 & 4 & 5 & 6 & 6 & 6 \\
\hline \multicolumn{3}{|c|}{ Abréviation : } & \multicolumn{5}{|c|}{ Références : } & \\
\hline \multicolumn{3}{|c|}{ 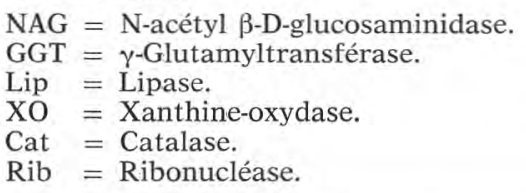 } & \multicolumn{5}{|c|}{$\begin{array}{l}\text { 1. Kitchen et al., } 1978 . \\
\text { 2. BAUMRUCKER, } 1979 . \\
\text { 3. MAJUMDER et GANGULI, } 1972 \text { b. } \\
\text { 4. ANDERSON, } 1982 \text {. } \\
\text { 5. STANNARD, } 1975 . \\
\text { 6. KITCHEN et al., } 1970 .\end{array}$} & \\
\hline
\end{tabular}


(Anderson, 1982). D'après Downey et Murphy (1975), l'interaction électrostatique entre la lipase de charge positive et le glycomacropeptide de la K-caséine joue un rôle primordial pour la liaison entre lipase et caséine. Quant à la prédominance d'une telle liaison ionique, les résultats d'Anderson (1982) ne coïncident cependant pas avec ceux des auteurs sus-mentionnés.

Les enzymes jouent un rôle important dans la transformation du lait, comme le montre l'exemple du fromage. Les essais effectués par notre institut ont montré que les activités enzymatiques diffèrent dans le lait de cuve et le lactosérum; plusieurs peptidases se signalent par une activité très faible et la phosphatase et la protéinase présentent des variations significatives (tab. 5).

TABLEAU 5 - TABLE 5

Enzymes dans le lait de cuve et le lactosérum

Enzymes in milk and whey

\begin{tabular}{|c|c|c|c|c|}
\hline & Lait 1 & $\begin{array}{l}\text { Lacto- } \\
\text { sérum } 1\end{array}$ & Lait 2 & $\begin{array}{l}\text { Lacto- } \\
\text { sérum } 2\end{array}$ \\
\hline \multirow{2}{*}{\multicolumn{5}{|c|}{ Peptidases }} \\
\hline & $2,62.10^{-2}$ & $3,35.10^{-2}$ & $2,70.10^{-2}$ & $3,58 \cdot 10^{-2}$ \\
\hline Leu & $1,77 »$ & $1,82 »$ & $2,08 »$ & $2,15 »$ \\
\hline Phe & $1,38 »$ & 0,98 » & 1,57 » & $0,93 »$ \\
\hline Pro & $0,77 »$ & 0,65 » & $0,55 »$ & $0,42 »$ \\
\hline Glu & $1,73 »$ & $1,08 »$ & $1,33 »$ & $0,95 »$ \\
\hline Lactate-déshydrogénase & 5,4 & 5,9 & 5,7 & 5,6 \\
\hline Lipase & 0,35 & 0,42 & 0,35 & 0,49 \\
\hline Phosphatase & 61 & 29 & 60 & 22 \\
\hline Protéinase & 132,1 & 68,8 & 108,7 & 67 \\
\hline
\end{tabular}

Toutes les activités sont indiquées en nanomoles de substrat transformé par min et par $\mathrm{ml}$ de lait ou de lactosérum à $25^{\circ} \mathrm{C}$, sauf la protéinase qui est indiquée en nanogrammes $/ \mathrm{min} / \mathrm{ml}$ à $35^{\circ} \mathrm{C}$ à $\mathrm{pH} 7$.

Substrats utilisés :

Peptidases : dérivés aminométhylcoumarine, $\mathrm{pH} 7,0$.

LDH : pyruvate, $\mathrm{pH} 7,0$.

Lipase : méthylumbelliférylheptanoate, $\mathrm{pH} 7,0$.

Phosphatase : p-nitrophénylphosphate, $\mathrm{pH} 10$.

Protéinase : caséine, $\mathrm{pH} 7,0$.

Le lait et le lactosérum proviennent de la fromagerie d'emmental d'Uettligen et ont été prélevés dans la même cuve ; $12 \%$ d'eau ont été ajoutés pour la fabrication du fromage. 
Pendant la maturation du fromage, les composants du lait subissent une série de modifications qui sont dirigées par les enzymes. En premier lieu, ce sont les enzymes présentes dans la présure et celles produites par les cultures qui interviennent dans ces processus. Dans les fromages fabriqués à base de lait cru, les enzymes originaires du lait y participent également. Cela a été mis en évidence pour les enzymes protéolytiques du fromage de Gouda, fabriqué dans des conditions aseptiques et sans adjonction de présure et de cultures. La présure est de première importance pour la protéolyse initiale de la caséine. Après les premiers mois de maturation, les enzymes bactériennes des cultures sont capables de déclencher une dégradation lente, mais intense de l' $\alpha_{s_{1}}$-et de la $\beta$-caséines, sans intervention de la présure. La protéase endogène du lait est responsable de la production des " caséines mineures " typiques, soit $\gamma, \mathrm{R}$, TS et $\mathrm{S}$ à partir de la $\beta$-caséine (Visser et De Groot-Mostert, 1977).

\section{Influences sur les activités enzymatiques}

Les méthodes de détermination enzymatique ne servent pas à mesurer la concentration d'une enzyme, mais elles sont destinées à déterminer son activité catalytique, soit sa capacité de déclencher la transformation spécifique d'un substrat déterminé par unité de temps. L'activité de chaque enzyme présente dans le lait est vraisemblablement influencée par un grand nombre de facteurs, tels que :

- la période de lactation ;

- la saison ;

- l'espèce de mammifère ;

- la race ;

- l'alimentation ;

- la santé mammaire, les mammites.

D'autres influences encore sont possibles.

Vu la multitude de données disponibles sur les enzymes, nous sommes obligés de limiter nos commentaires à quelques-uns des résultats obtenus.

\section{a) Période de lactation}

La composition du lait change au cours de la lactation. Ces changements se manifestent de la façon la plus prononcée dans les premiers jours de la (nouvelle) lactation. Pendant cette période, la teneur en substances actives du lait s'accroît considérablement (Blanc, 1981). Il en est de même de plusieurs enzymes.

L'activité de l' $\alpha$-amylase, de la catalase, de la peroxydase et de la phosphatase acide est abaissée dans le lait mûr de vache et de femme par rapport au colostrum et seule celle de la lipase est augmentée (Wüthrich et al., 1963). 
Pour la $\beta$-glucuronidase, on constate une forte activité dans le colostrum bovin pendant la première journée (supérieure à 10 unités) qui, après 3 jours, s'abaisse à la valeur usuelle mesurée dans le lait de vache (inférieure à 1 unité) (Kiermeier et Gull, 1968). En revanche, l'activité de la lactoperoxydase se signale par une valeur initiale basse dans la première phase colostrale (première traite après le vêlage) ; elle augmente rapidement pour atteindre le maximum entre le $3^{\mathrm{e}}$ et le $5^{\mathrm{e}}$ jour et s'abaisse ensuite à la valeur normale du lait de vache (Kiermeier et Kuhlmann, 1972 a). De même, pour les phosphatases alcaline et acide, l'activité est très forte pendant la première période colostrale ; cette activité enzymatique diminue jusqu'au $40^{\mathrm{e}}$ jour pour la phosphatase acide, alors que celle de la phosphatase alcaline baisse au minimum après 10 jours (Kiermeier et Meinl, 1961).

Dans le lait mûr, les changements enzymatiques ne semblent plus être très importants, à l'exception de la phosphatase alcaline dont l'activité croît continuellement après le $10^{\mathrm{e}}$ jour, pour atteindre ou dépasser la valeur initiale à la fin de la lactation (Kiermeier et Meinl, 1961 ; Linden et Ged, 1976). La peroxyde-dismutase et la xanthineoxydase ne présentent pas de modifications significatives entre les jours 0 et 300 (Holbrook et Hicks, 1978).

$\begin{array}{rrrl} & & \text { PD } & \text { XO } \\ \text { Jours } & 0-100 & 1,05 & 0,078 \mathrm{U} / \mathrm{ml} \\ & 101-200 & 1,08 & 0,066 \\ 201-300 & 1,17 & 0,063\end{array}$

Cependant, Hicks (1980) n'écarte pas l'idée d'une possibilité de démontrer l'augmentation de l'activité de la peroxyde-dismutase au cours de la lactation dans le lait, si l'on prend une grande population en considération. L'activité de la phosphatase acide se maintient également à peu près constante après le $40^{\circ} \mathrm{j}$ (Kiermeier et Meinl, 1961).

\section{b) Saison}

Les recherches que nous avons réalisées sur l'influence des traitements thermiques sur les composants les plus importants du lait nous ont permis de constater que le lysozyme subit des fluctuations significatives au cours de l'année, sa teneur étant inférieure pendant les mois d'été à celle d'hiver (fig. 2). Par contre l'amylase, la peroxydase et la xanthine-oxydase ne présentent pas de variations saisonnières remarquables (Blanc, 1980).

L'abaissement de l'activité de la peroxyde-dismutase pendant les mois de mars, d'avril et de mai est probablement associé au vêlage d'un grand nombre de vaches pendant cette période. Les changements intervenant dans les autres mois de l'année sont insignifiants (Hicks, 1980). En hiver, l'activité de la phosphatase acide est en moyenne de $40 \%$, celle de la phosphatase alcaline de $10 \%$ supérieure aux valeurs de l'été (Kiermeier et Meinl, 1961). 


\section{LYSOZYME}

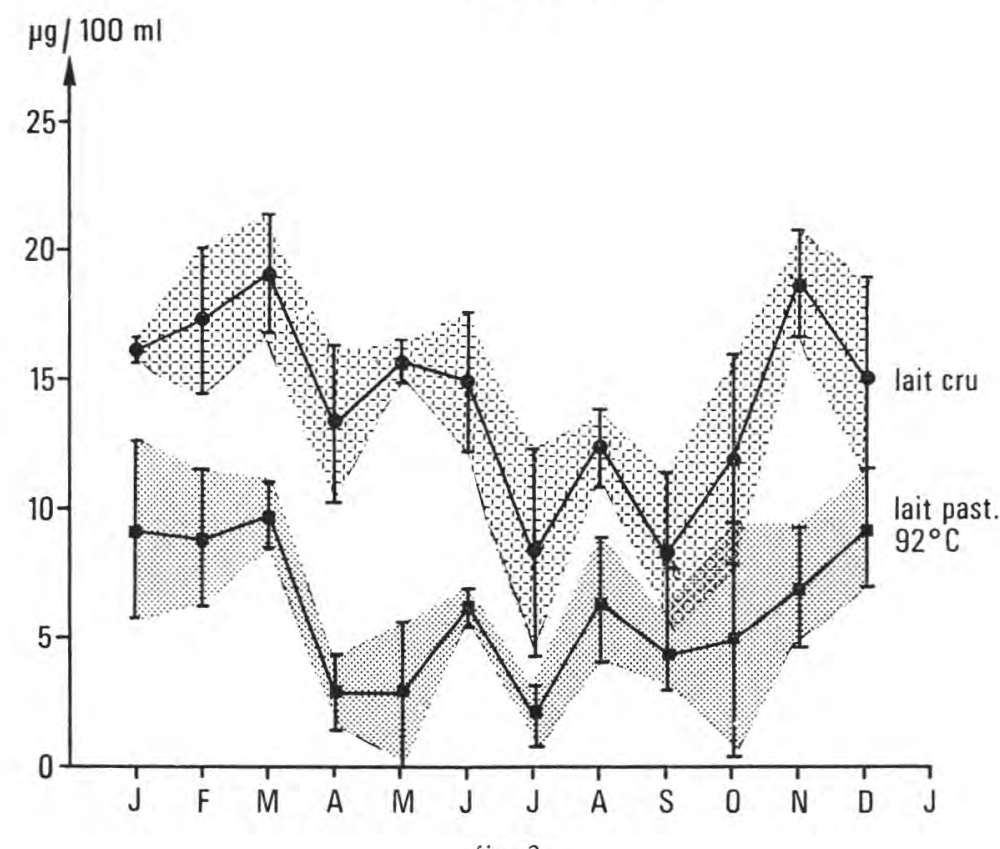

fig. 2

Variations mensuelles de la teneur en lysosyme du lait cru et pasteurisé (d'après BLANC, 1980).

Monthly variations of lysozyme content in raw and pasteurized milk (from BLANC, 1980).

\section{c) Espèce de mammifère}

Les laits des divers mammifères se différencient non seulement par leur composition, mais aussi par leurs activités enzymatiques. En partie, ces différences sont remarquables, comme le montre l'exemple du lysosyme, de la lipase et de la ribonucléase (tab. 6). Quant au lysozyme, le lait de jument (Jauregui-Adell, 1975) et le lait humain présentent l'activité la plus forte, suivis des laits de chèvre, de vache et de brebis, alors que cette enzyme n'a pas été décelée dans le lait de truie. Pour l'action de la lipase et de la ribonucléase, l'ordre des laits des mammifères mentionnés est différent (Chandan et al., 1968).

Les recherches les plus approfondies ont été consacrées aux laits de vache et de femme. Pour ces deux laits, le tableau 1 présente les valeurs relatives de quelques enzymes (Shahani et al., 1980). 


\section{TABLEAU 6 - TABLE 6}

Teneur en lysozyme, lipase et ribonucléase du lait de différents mammifères Lysozyme, lipase and ribonuclease contents of milk from mammals

\begin{tabular}{l|c|c|c|c}
\hline \multicolumn{1}{c|}{ Mammifère } & $\mathrm{N}$ & $\begin{array}{c}\text { Lysozyme } \\
\mu \mathrm{g} / 100 \mathrm{ml}\end{array}$ & $\begin{array}{c}\text { Lipase } \\
\mu \mathrm{M} / \mathrm{min} / 100 \mathrm{ml}\end{array}$ & $\begin{array}{c}\text { Ribonucléase } \\
\mu \mathrm{g} / 100 \mathrm{ml}\end{array}$ \\
\hline Femme & 3 & 40000 & 13 & 305 \\
Vache & 3 & 13 & 132 & 1100 \\
Chèvre & 3 & 25 & 39 & 425 \\
Brebis & 4 & 10 & 9 & 300 \\
Truie & 3 & 0 & 141 & 30 \\
Jument & & $79000(1)$ & - & - \\
\hline
\end{tabular}

D'après Chandan et al., 1968.

(1) D'après JaURegui-Adell, 1975.

\section{d) Race}

Même pour le lait d'un seul mammifère, on note des différences dans les activités enzymatiques, qui peuvent varier selon la race. Ainsi, le lait de vaches de la race Jersey montre des activités enzymatiques accrues pour la peroxyde-dismutase $(1,27 \mathrm{U} / \mathrm{ml})$ et la xanthine-oxydase $(0,0775 \mathrm{U} / \mathrm{ml})$ par rapport à celles du lait de vaches de la race Holstein (respectivement 0,92 et $0,065 \mathrm{U} / \mathrm{ml}$ (Holbrook et Hicks, 1978).

\section{e) Alimentation}

L'influence de la nourriture sur les activités enzymatiques a été étudiée à plusieurs reprises pour le lait de femme (tab. 7). Dans le lait de vache, on n'a constaté aucun effet de l'affouragement sur l'activité des phosphatases acide et alcaline (Kiermeier et Meinl, 1961). Par contre, on a trouvé un rapport statistiquement assuré entre l'alcalinité du sol et la teneur en xanthine-oxydase du lait de vache (Kiermeier et Vogt, 1956 b) qui, d'après Kiermeier et Capellari (1957) est imputable à la teneur en molybdène du fourrage. Cependant, l'administration de molybdate de sodium à des vaches et à des chèvres ayant reçu auparavant une diète pauvre en molybdène, malgré l'augmentation de la concentration en molybdène, n'a pas d'influence sur l'activité de la xanthine-oxydase du lait de ces mammifères (Hart et al., 1967). 


\section{TABLEAU 7 - TABLE 7}

Influence de composants alimentaires sur les activités enzymatiques du lait maternel

Influence of dietary components on enzymic activities of maternal milk

\begin{tabular}{|c|c|c|c|}
\hline $\begin{array}{l}\text { Composant } \\
\text { alimentaire }\end{array}$ & Influence & $\begin{array}{l}\text { Enzyme } \\
\text { influencée }\end{array}$ & Référence \\
\hline Matière grasse & + & $\begin{array}{c}\text { Lipase } \\
\text { Estérase } \\
\text { Phosphatase alcal. } \\
\text { Phosphatase acide }\end{array}$ & $\begin{array}{l}\text { KARMARKAR et } \\
\text { RAMAKRISHNAN, } \\
1959\end{array}$ \\
\hline Protéines & + & $\begin{array}{l}\text { Phosphatase alcal. } \\
\text { Xanthine-oxydase }\end{array}$ & $\begin{array}{l}\text { BeLAVADY, } 1960 \\
1962\end{array}$ \\
\hline Protéines + vitamines & - & $\begin{array}{c}\text { Lipase } \\
\text { Estérase } \\
\text { Phosphatase alcal. }\end{array}$ & $\begin{array}{l}\text { KARMARKAR et } \\
\text { al., } 1963\end{array}$ \\
\hline Vitamines & - & $\begin{array}{l}\text { Glucose-6-phosphate- } \\
\text { déshydrogénase }\end{array}$ & $\begin{array}{l}\text { SKLAVUNU- } \\
\text { ZURUKZOGLU et } \\
\text { al., } 1965\end{array}$ \\
\hline Vitamines & - & $\begin{array}{l}\text { Xanthine-oxydase } \\
\text { Lactate-déshydrogén. } \\
\text { Malate-déshydrogén. }\end{array}$ & $\begin{array}{l}\text { DEODHAR et al., } \\
1964\end{array}$ \\
\hline
\end{tabular}

\section{f) Mammites}

Le lait bovin provenant des mamelles atteintes de troubles sécrétoires présente d'importantes altérations non seulement dans sa composition chimique, mais aussi dans l'activité de certaines enzymes. Ces changements sont les conséquences d'une série d'incidents provoqués par l'invasion et la croissance de bactéries pathogènes dans la mamelle. Parmi ces incidents, il convient de mentionner l'entrée de leucocytes polymorphonucléaires dans la glande mammaire et dans le lait et la destruction de cellules et de structures tissulaires. Cela conduit à une capacité réduite de synthèse et à une diffusion accrue de sang et de composés cellulaires dans le lait (Schultz, 1977). Il est évident que ces altérations affectent aussi les enzymes. On sait que les mammites intensifient l'activité d'un grand nombre d'enzymes, celles dont l'action n'est pas influencée, voire diminuée, sont rares (Kiermeier et Kuhlmann, 1972 b). Le tableau suivant (fig. 3) présente un choix de résultats relatifs à l'influence des mammites sur les activités enzymatiques, publiés pendant les 15 dernières années.

Outre les enzymes déjà mentionnées, il convient de signaler la xanthine-oxydase (Hicks, 1980), l'aryl-sulfatase (Kitchen, 1976), la 


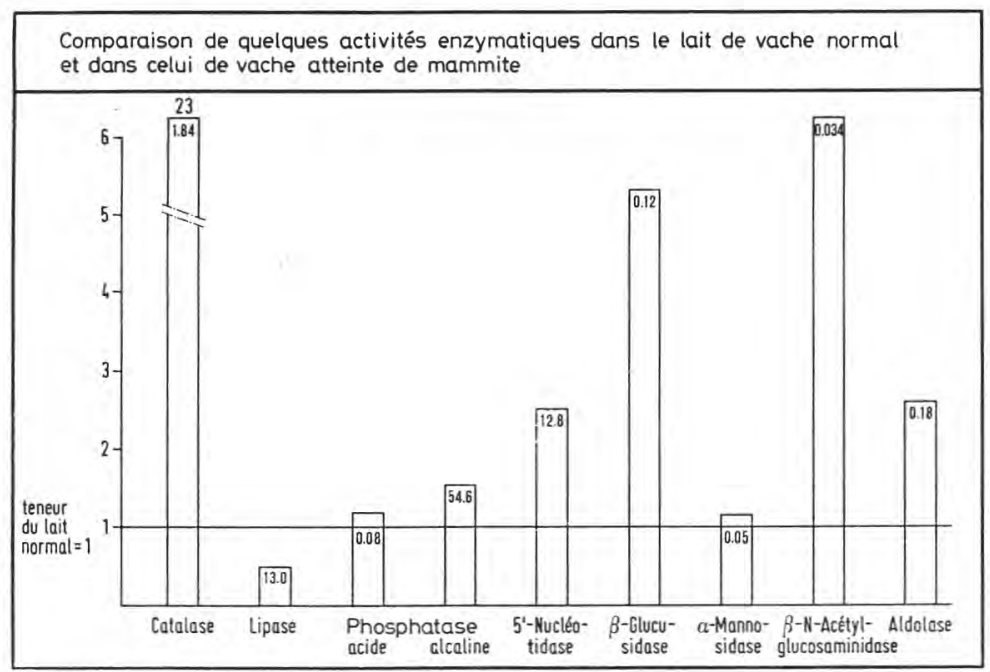

fig. 3

Comparaison de quelques activités enzymatiques dans le lait de vaches normales et dans celui de vaches atteintes de mammites (les valeurs inscrites dans les colonnes indiquent les activités des différentes enzymes) (d'après ANDERSON, 1977, 1982 ; ERWIN et RANDOLPH, 1975 ; Kitchen, 1976 ; Kitchen et al., 1978).

Comparison of some enzymic activities in milks from healthy and mastitis infected cows (values shown in columns are activities from different enzymes) (from ANDERSON, 1977, 1982; ERWIN and RANDOLPH, 1975; KITCHEN, 1976; Kitchen et al., 1978).

$\mathrm{N}$-acétyl- $\beta$-glucosidase (Anderson, 1977), la $\beta$-glucosidase (Kitchen, 1976 ; Kitchen et al., 1978), la lactate-déshydrogénase (Sommer et Sonneck, 1980 ; Bogin et Ziv, 1973), la glutamique-oxaloacétique transaminase (Bogin et Ziv, 1973), la carboxylestérase et la phospholipase (Fitz-Gerald et al., 1981), dont la teneur est également accrue dans le lait de mammite ; l'activité de la peroxyde-dismutase (Hicks, 1980) et celle de la phosphodiestérase (Anderson, 1977) est pratiquement inchangée, tandis que, d'après Kitchen (1970) et Erwin et Randolph (1975), la teneur de la xanthine-oxydase est abaissée.

Tenant compte de ces altérations, on a examiné la possibilité d'utiliser les enzymes comme élément diagnostique de routine des laits provenant d'animaux atteints de mammite.

Dans une des analyses comparant les enzymes phosphatase acide, $\mathrm{N}$-acétyl- $\beta$-D-glucosaminidase, $\beta$-glucuronidase, aryl-sulfatase, $\alpha$-mannosidase et catalase dans des échantillons de lait de quartiers présentant des nombres restreints ou élevés de cellules somatiques, il s'est avéré que la détermination spectrophotométrique de l'activité de la N-acétyl- 
$\beta$-D-glucosaminidase dans le lait bovin, avec un coefficient de corrélation de 0,84 , serait une méthode appropriée pour déterminer le nombre de cellules (Kitchen, 1976) et elle serait sans doute un instrument diagnostique précieux dans le programme de contrôle des mammites (Kitchen et al., 1980). Une adaptation de cette méthode pour être appliquée comme procédé fluorométrique créerait la base nécessaire à la mise au point d'un procédé automatisable (Kitchen et al., 1978). De même, entre le nombre de cellules et l'activité de la lactate-déshydrogénase et de leur isoenzyme $\alpha$-HBDH ( $\alpha$-hydroxybutyrate-déshydrogénase), il existe d'étroites interdépendances (Sommer et Sonneck, 1980).

Le lait de vache provenant de quartiers atteints de mammite subclinique manifeste des activités enzymatiques modifiées ; pour la leucine-aminopeptidase, l'activité enzymatique est le double de celle de lait extrait de quartiers sains (Eichel, 1981).

\section{g) Autres influences}

Nous ne possédons que peu d'informations sur d'autres facteurs susceptibles d'influencer les activités enzymatiques du lait, comme par exemple :

- le moment de la traite (matin et soir);

- Ie début et la fin de la traite ;

- la différence entre les quartiers ;

- le nombre de lactations.

Il s'est avéré que la traite du soir et la traite du matin n'entrấnent pas de différences dans la concentration en peroxyde-dismutase du lait bovin (Holbrook et Hicks, 1978).

Pour l'activité de la leucine-aminopeptidase, on note des variations entre les laits des différents quartiers, mais seulement chez certaines vaches (Eichel, 1981). Une comparaison des taux de lysozyme de laits provenant des quartiers gauche et droit et des quartiers antérieur et postérieur n'aboutit pas à des résultats clairs (Meyer et Senft, 1979).

Pendant la traite, la concentration de lysozyme se maintient plus ou moins constante dans les laits de quartiers sains; pour les quartiers atteints de troubles de la sécrétion, elle diminue d'abord pour augmenter de nouveau à la fin de la traite (Meyer et Senft, 1979). Dans le lait de vaches ayant vêlé quatre fois ou plus, l'activité de la phosphatase alcaline est abaissée dans les échantillons prélevés 24 semaines ou plus après le dernier vêlage (Linden et Ged, 1976).

\section{Rôle et importance des enzymes}

Le lait contient une grande variété d'enzymes (tab. 1), mais pour la plupart d'entre elles, le rôle et l'importance qu'elles pourraient avoir pour le lait sont difficiles à définir. Car un grand nombre 
d'enzymes ne disposent pas du substrat dont elles auraient besoin pour exercer leur activité catalytique; pour d'autres les conditions d'environnement sont défavorables. Cependant, les enzymes sont importantes, comme indicatrices de certains changements, dus aux traitements technologiques d'une part, et sur le plan nutritionnel d'autre part.

\section{a) Importance technologique des enzymes du lait}

L'importance technologique des enzymes du lait peut être envisagée sous différents angles (Fox et Morrissey, 1981) : soit du point de vue :

- des changements positifs ou négatifs de la qualité du lait ;

- des traitements thermiques du lait ;

- des mammites (cet aspect a déjà été discuté) ;

- de l'activité microbienne ;

- comme source commerciale d'enzymes, la ribonucléase étant au premier plan.

Il est évident que non seulement les enzymes originaires du lait, mais aussi les enzymes produites par les bactéries interviennent dans les différents processus étudiés.

Les enzymes qui participent à la modification, positive ou négative, de la qualité du lait sont les oxydo-réductases, soit la lactoperoxydase, la xanthine-oxydase, la peroxyde-dismutase, la sulfhydryl-oxydase ainsi que les hydrolases, à savoir la lipase, la protéase, la phosphatase acide.

Parmi les oxydo-réductases, la catalase, la lactoperoxydase et la xanthine-oxydase ont un effet oxydant, alors que la peroxydedismutase est un antioxydant. La catalase est capable, par l'effet catalysateur du fer hémique qu'elle contient, d'oxyderl'acidelinoléique (Eriksson, 1970). Comme il a été démontré, la xanthine-oxydase (Beauchamp et Fridovich, 1970) et la lacto-peroxydase peuvent produire, par l'oxydation d'épinéphrine, (Hill, 1977), ou par l'irradiation du lait avec de la lumière fluorescente en présence de riboflavine des anions peroxyde ; de tels anions ont déjà été trouvés dans du lactosérum exposé à la lumière (Korycka-Dahl et Richardson, 1978, 1979). On n'a cependant pas encore élucidé s'ils sont formés dans le lait sous l'influence de la lactoperoxydase. L'anion peroxyde joue un rôle décisif pour les modifications oxydatives du lait ; il se décompose en oxygène singulet, en radicaux hydroxyles et en eau oxygénée selon la réaction suivante :

$$
\begin{aligned}
& 2 \mathrm{O}_{2}^{-}+2 \mathrm{H}^{+}+\longrightarrow \mathrm{H}_{2} \mathrm{O}_{2}+\mathrm{O}_{2} \\
& \mathrm{H}_{2} \mathrm{O}_{2}+\mathrm{O}_{2}+\mathrm{H}^{+} \longrightarrow \rightarrow \mathrm{HO}^{-}+{ }^{1} \mathrm{O}_{2}+\mathrm{H}_{2} \mathrm{O}
\end{aligned}
$$

Ces produits de décomposition interviennent directement dans le déclenchement de l'oxydation des lipides (Aurand et al., 1977 ; Kellogg et Fridovich, 1975 ; Pederson et Aust, 1973). La peroxyde- 
dismutase a été décelée à plusieurs reprises dans le lait bovin (Asada, 1976 ; Hicks et al., 1975, Hill, 1975 ; Holbrook et Hicks, 1978 ; KoryckaDahl et al., 1979). Lorsque le lait est stocké dans des conditions dans lesquelles l'anion peroxyde ne surcharge pas l'enzyme (Hicks, 1980), celle-ci peut agir comme agent protecteur en catalysant la dismutation du radical du peroxyde en oxygène triplet et en eau oxygénée (réaction 1) (Michelson et al., 1977). L'eau oxygénée ainsi produite peut être réduite sous l'influence de la catalase ou de la peroxydase.

Par contre, la présence de la peroxyde-dismutase ne peut pas prévenir l'oxydation et la destruction des composants du lait par les anions peroxyde se formant sous l'influence de la lumière à laquelle le lait est exposé. Cela n'est possible que par un entreposage du lait dans l'obscurité (Korycka-Dahl et Richardson, 1978). La peroxydedismutase est thermostable dans le lactosérum obtenu par centrifugation à 20000 tours par minute pendant $1 \mathrm{~h}$ jusqu'à une température de $71^{\circ} \mathrm{C}$; à des températures supérieures, son activité se perd rapidement (Hicks et al., 1979). La pratique actuelle de pasteurisation à des températures accrues occasionne des pertes significatives de cette enzyme, ce qui, selon Hicks et al. (1979), affecte la stabilité oxydative des produits laitiers.

La sulfhydryl-oxydase est susceptible d'oxyder des groupements sulfhydryle de la cystéine, du glutathion et de protéines en disulfures correspondants en formant de l'eau oxygénée. Elle peut aussi atté nuer significativement le goût de cuisson du lait (Shipe et al., 1975). Les lipases du lait, lors de l'hydrolyse de la matière grasse, peuvent donner lieu à un faux goût du lait et des produits laitiers, la rancidité (Arnold et al., 1975). Cependant, il n'existe pas de corrélation significative entre l'activité des lipases et la lipolyse spontanée s'opérant dans le lait bovin (Chilliard, 1982). En outre, les lipases participent au développement de l'arôme des fromages à moisissure bleue.

La protéase alcaline est partiellement résistante aux traitements U.H.T. - pour une inactivation totale, il est recommandé d'appliquer un traitement U.H.T. à $142^{\circ} \mathrm{C}$ pendant $16 \mathrm{~s}$ (Driessen et Van der Waals, 1978) - et elle résiste entièrement aux conditions de pasteurisation. Cela conduit à une protéolyse au cours du stockage et, par conséquent, modifie les propriétés du lait et des produits laitiers (arôme, consistance) ; la formation de gel et l'épaississement par vieillissement du lait ayant subi un traitement UHT (direct) sont attribuables à la présence de protéases, à la fois originaires du lait et extracellulaires en provenance de micro-organismes psychrotrophes (Fox, 1981 ; Law, 1979 ; Mottar, 1981 ; Visser, 1981). La protéase acide semble participer à la protéolyse se déroulant dans le fromage, ce qui ressort d'analyses de fromages ayant été fabriqués dans des conditions aseptiques et sans addition de chymosine (rennine) et de cultures (Visser et De Groot-Mostert, 1977). 
Le traitement thermique du lait inactive les enzymes à des degrés variables. La figure 4 montre les droites de l'inactivation de différentes enzymes dans un diagramme semi-logarithmique temps - température. La phosphatase alcaline est inactivée dans les conditions d'un chauffage rapide, la peroxydase dans celles d'un traitement thermique à haute température. L'absence de ces deux enzymes est utilisée depuis longtemps pour démontrer que la pasteurisation effectuée a été suffisante, et elle passe pour une preuve que le lait est exempt de

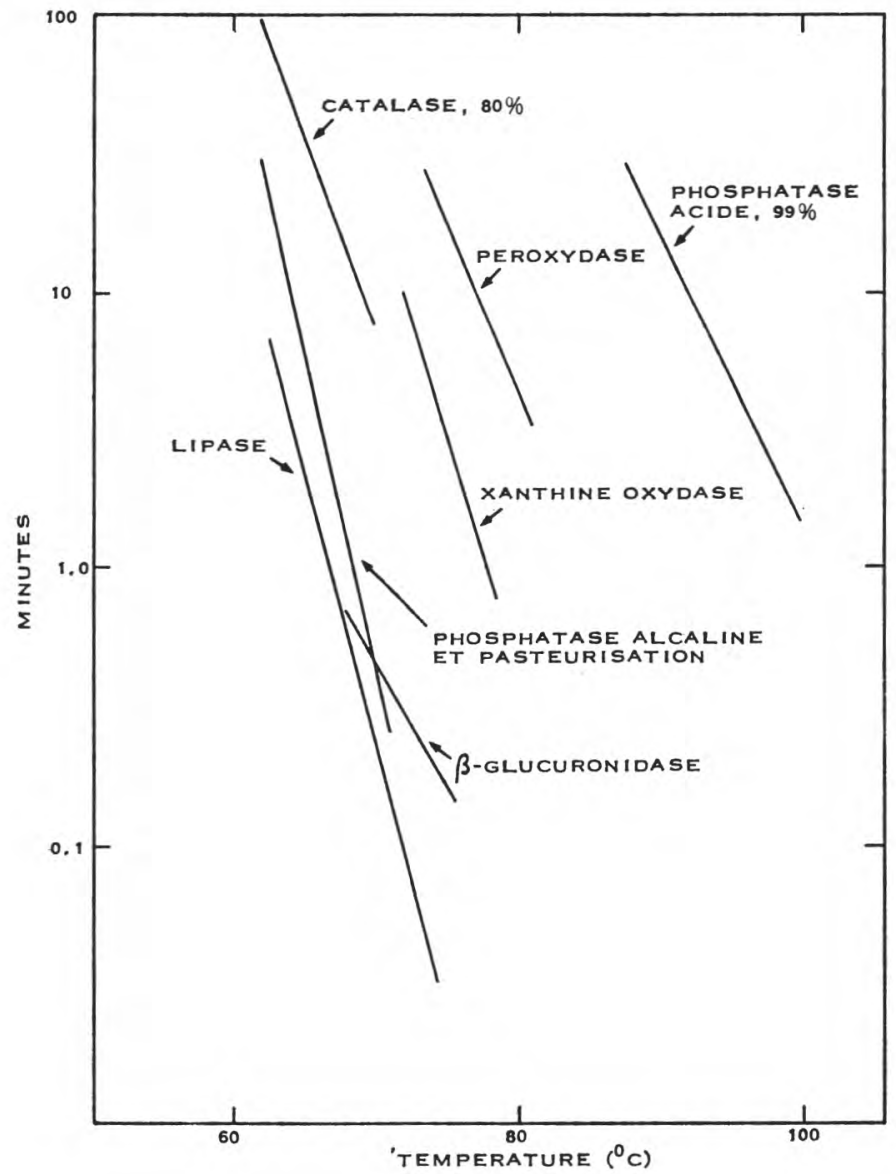

fig. 4

Conditions temps/température nécessaires à l'inactivation de certaines enzymes du lait (d'après Jenness et Patton, 1967 ; Kiermeier et DoruK, 1972).

Time/temperature conditions to inactivate some enzymes in milk (from JENNESs and PatTon, 1967; KIERMEIER and DORUK, 1972). 
germes pathogènes, car leur destruction survient à des températures de chauffage inférieures à celle de l'inactivation de ces deux enzymes (Ritter, 1949 ; Pasche, 1953).

Le lysosyme et le système de la lactoperoxydase ont des effets antibactériens. Le lysozyme catalyse l'hydrolyse de la paroi cellulaire des bactéries. In vitro plusieurs bactéries gram-positives et gramnégatives sont sensibles au lysozyme du lait de vache et de femme, Micrococcus lysodeikticus et Sarcina lutea, par ex., et, en association avec le chlorure de sodium et le tétra-acétate d'éthylène-diamine, Escherichia coli et Bacillus cereus (Vakil et al., 1969).

Le système de la lactoperoxydase comprend comme enzyme la lactoperoxydase ainsi que le thyocyanate $\left(\mathrm{SCN}^{-}\right)$et l'eau oxygénée ; l'enzyme catalyse l'oxydation du thiocyanate par l'eau oxygénée (Reiter, 1978). C'est un système naturel antibactérien (Reiter et Härnulv, 1982), il a été proposé pour prévenir la détérioration rapide du lait dans les conditions pratiques à Sri Lanka et au Kenya (Björck et al., 1979; Härnulv et Kandasamy, 1982). Il exerce une influence bactériostatique sur :

- des bactéries de cultures utilisées dans la fabrication de fromages : Streptococcus thermophilus, lactobacilles thermophiles ;

- agents pathogènes des mammites : Str. agalactiae et uteris ;

- organismes indésirables du lait : flore du lait cru ;

et des effets bactéricides sur :

- des agents pathogènes des mammites : Staphylococcus aureus; Escherichia coli ;

- des micro-organismes pathogènes et entéropathogènes : Salmonella typhosa, paratyphi, typhimurium ; Escherichia coli ; Pseudomonas aeruginosa; Streptococcus pyogenes ;

- micro-organismes nocifs du lait : Pseudomonas fluorescens souches gram-négatives, flore du lait cru (Björck, 1982).

\section{b) Importance nutritionnelle des enzymes du lait}

L'information que nous possédons sur l'importance générale des enzymes ingérées avec la nourriture et leur rôle dans la digestion est très limitée. D'après Ammon (1969), le pH de l'estomac conduit à l'inactivation des enzymes alimentaires, de sorte qu'elles doivent être considérées comme insignifiantes par rapport aux enzymes sécrétées dans le tube digestif.

Il en est tout autrement pour le nouveau-né humain, chez lequel les activités des enzymes de la digestion sont en partie peu développées et chez lequel le $\mathrm{pH}$ stomacal est nettement moins acide que chez l'adulte. Cela influence surtout la digestion des graisses. Ainsi, l'intestin grêle des nourrissons et en particulier des enfants nés avant terme présente une concentration de sels biliaires insuffisante pour la digestion de monoglycérides et d'acides gras libres. La quan- 
tité de sels biliaires est cependant suffisante pour activer la lipase inactive contenue dans le lait maternel en plus de la lipoprotéinelipase (Hernell et Olivecrona, $1974 \mathrm{a}, \mathrm{b}$ ). Stimulée par les sels biliaires et grâce à sa concentration dans le lait, la lipase peut hydrolyser presque entièrement en moins de $30 \mathrm{~min}$, la matière grasse du lait dans les conditions $\mathrm{du} \mathrm{pH}$ de l'intestin grêle et du taux d'acide cholique. Cela facilite considérablement la résorption de la graisse chez les nouveau-nés (Olivecrona et Hernell, 1976) et pourrait expliquer le fait que les graisses du lait maternel sont résorbées plus efficacement que celles d'aliments infantiles artificiels, surtout lorsque la concentration en sels biliaires dans l'intestin grêle est basse (Signer et al., 1974). De même, l'activité protéolytique et la présence de l'aamylase dans le lait maternel sont sans doute avantageuses pour le nouveau-né (Storres et Hull, 1956; Hanafy et al., 1971).

Dans l'alimentation d'animaux nouveau-nés et de nourrissons, le lysosyme et la lactoperoxydase sont des enzymes très importantes à cause de leur effet antibactérien signalé ci-dessus.

\section{c) Intérêt spécial de quelques enzymes importantes}

\section{Protéases}

Plusieurs protéases ont été mises en évidence dans le lait (Humbert et Alais, 1979 ; Fox, 1981), par exemple la protéase alcaline et la protéase acide. La protéase alcaline possède des propriétés semblables à celle de la trypsine; son $\mathrm{pH}$ optimal est de $7,5-8,0$. Ses caractéristiques moléculaires et enzymatiques ainsi que les résultats chromatographiques signalent son identité avec la plasmine du sérum sanguin (Kaminogawa et al., 1972 ; Eigel et al., 1979 ; Reimerdes et al., $1981 \mathrm{a}, \mathrm{b})$. Cette protéase est capable de dégrader la caséine en plusieurs protéines et peptides plus petits. Au cours de cette décomposition, la $\beta$-caséine se transforme en $\gamma_{1^{-}}, \gamma_{2}, \gamma_{3}$-caséines (Eigel, 1977 ; Eigel et al., 1979), et en composants 5 (Eigel, 1981 ; Andrews, 1978 a), 8-slow (Eigel et Keenan, 1979) et 8-fast (Andrews, 1978 b) de la fraction protéose-peptone. L' $\alpha_{\mathrm{si}-\mathrm{c}}$-caséine se transforme parallèlement en $\lambda$-caséine (Aimutis et Eigel, 1982).

Le pH optimal de la protéase acide est de 4,0 (Kaminogawa et Yamauchi, 1972). Elle semble intervenir dans la protéolyse du fromage (Visser et De Groot-Mostert, 1977).

Outre l'activité protéolytique, on a décelé dans le lait bovin, porcin et humain, en particulier dans le colostrum, des inhibiteurs de la trypsine (Laskowski et Laskowski, 1951 ; Laskowski et al., 1957 ; Lindberg, 1979 ; Von Fellenberg et Horber, 1980). On trouve dans le colostrum bovin quatre inhibiteurs de la protéase, dans le lait bovin un inhibiteur $\alpha_{1}$ de la protéase du sérum sanguin en doses nettement identifiables et des traces de la macroglobuline $\alpha_{2}$ (Von Fellenberg et Horber, 1980). 


\section{Phosphatases}

La détermination de la phosphatase alcaline sert d'indicateur d'un traitement thermique; plusieurs méthodes ont été mises au point récemment. Murthy et al. (1978) ont développé une méthode colorimétrique rapide et Monget et Laviolette (1978) un microtest API ZYM. Linden et Paquet (1981) ont proposé un procédé permettant de mesurer l'activité de la phosphatase alcaline dans le lait et la crème rendus transparents à l'aide d'un substrat tampon et d'un mélange dissolvant. Cette enzyme est inactivée dans le lait et la crème ayant subi peu avant un court traitement thermique à haute température (entre 80 et $100^{\circ} \mathrm{C}$ ), mais elle a tendance à se réactiver. Plusieurs auteurs se sont occupés de ce phénomème et ont essayé de l'interpréter (Brown, 1940 ; Siegenthaler, 1954 ; Paschke, 1958 ; Kresheck et Harper, 1967 ; Fram, 1957 ; Ngoc-Du et al., 1965 ; Sharma et Ganguli, 1971, 1974 ; Wright et Tramer, 1953 a, b, 1954 ; Lyster et Aschaffenburg, 1962 ; Murthy et al., 1976 ; Peereboom, 1970 ; Linden, 1979). Dans le lait stérilisé par friction, chauffé à $140^{\circ} \mathrm{C}$, on a également pu observer une réactivation de cette enzyme allant jusqu'à 6,6\% (Ged et Alais, 1976). La phosphatase alcaline est une métalloglycoprotéine. Elle contient du zinc et du magnésium, est stimulée par $\mathrm{Mg}^{2+}$ (Linden et Alais, 1976 ; Linden et al., 1977) et peut être enrichie 7440 fois à partir de babeurre (Linden et al., 1974). Son poids moléculaire se situe entre 170/000 et 190/000 daltons (Andrews, 1965 ; Barman et Gutfreud, 1966 ; Linden et al., 1974 ; Mather et Keenan, 1974). Elle apparaît sous forme de dimères avec deux sousunités identiques ou très semblables (Linden et Alais, 1976). Elle peut déphosphoryser la caséine (Lorient et Linden, 1976). L'enzyme est liée aux particules lipoprotidiques de la membrane des globules gras, et dans le lait il existe une corrélation entre l'activité de l'enzyme et le taux de matière grasse (Linden et Ged, 1976). La phosphatase alcaline est réactivée jusqu'à $1 \%$ dans le lait chauffé. Pour une réactivation plus forte il faut la présence de $\mathbf{M g}^{2+}$ et du substrat $\beta$-glycérophosphate dans le lait chauffé ; une réactivation de $10 \%$ a été obtenue avec du $\mathrm{MgSO}_{4}$ et du $\beta$-glycérophosphate.

Le $\mathrm{Mg}^{2+}$ exerce son effet de réactivation maximum à une concentration inférieure à $0,1 \mathrm{M}$ et stimule l'enzyme résiduelle tandis que le $\mathrm{Zn}^{2+}$ qui est fixé au centre actif est susceptible de réactiver l'apoenzyme. Quand on sépare l'enzyme du lait chauffé pour l'incuber dans une solution de $\beta$-glycérophosphate, de $\beta$-lactoglobuline et de ions magnésium, 10 à $30 \%$ de son activité enzymatique originale réapparaissent (Wright et Tramer, 1956 ; Lyster et Aschaffenburg, 1962 ; Murthy et al., 1976 ; Linden, 1979).

\section{Lysozymes}

En plus des considérations présentées au chapitre 4, lettres b et c, signalons que Pahud et Widmer (1982) n'ont pas pu mettre en évidence l'activité du lysozyme dans le lactosérum du colostrum et 
du lait. Par contre, elle a été décelée par plusieurs auteurs dans le lait bovin (Chandan et al., 1968 ; Meyer et Senft, 1979 ; Blanc, 1980). Le lysozyme du lait de vache a été enrichi en lysozyme obtenu de lactosérum acide et purifié (Chandan et al., 1965). La molécule lysozyme contient 154 acides aminés alors que celle du lait maternel en renferme 124. Elle est thermostable à $\mathrm{pH} 7.0$ et thermolabile à $\mathrm{pH} 9.0$ (Parry et al., 1969 ; Eitenmiller et al., 1976).

\section{Lactoperoxydase}

La lactoperoxydase est une hémoprotéine contenant environ $0.07 \%$ de fer et 8 à $10 \%$ de glucides. Son groupement prosthétique est constitué de protohèmes (Sievers, 1979).

Carlström (1969) suppose que cette enzyme est composée de deux sous-unités presque identiques, qui peuvent encore être subdivisées ; après analyse de la sédimentation, de la teneur en fer et de la composition en acides aminés, le poids moléculaire d'un composant a été fixé à $78 / 500$ et de l'autre à 76/500. Cette enzyme est séparée en 5 fractions sur colonne Séphadex-DEAE (Paul et al., 1980). Par contre, les analyses de Sievers (1981) avec SDS-PAGE et scission au moyen de $\mathrm{CNBr}$ ont montré que la lactoperoxydase consiste en une seule chaîne polypeptidique avec leucine comme acide aminé terminal et que le poids moléculaire coïncide avec les valeurs indiquées par Carlström (1969). La structure secondaire de cette protéine est constituée par la $\beta$-structure à $65 \%$, la structure $\alpha$-hélicoïdale à $12 \%$ et une structure non-ordonnée à $12 \%$ (Sievers, 1980).

\section{Xanthine-oxydase}

Le cardiologue américain Oster (1974) soutient l'hypothèse que la xanthine-oxydase du lait homogénéisé est un autre facteur de risque dans l'étiologie de cardiopathies coronaires. D'après cette théorie, la xanthine-oxydase est résorbée, sous forme enzymatiquement active, par la muqueuse de l'intestin grêle, transportée par la lymphe au myocarde et aux parois artérielles où elle se dépose. Dans les parois artérielles, la membrane cellulaire est lésée par l'oxydation des aldéhydes du plasmalogène. C'est ainsi que se déclencherait la genèse de l'artériosclérose. La xanthine-oxydase est relativement thermostable. Ce n'est qu'après un chauffage à $75^{\circ} \mathrm{C}$ pendant $5 \mathrm{~min}$ (Demott et Praepanitchai, 1978) ou à $85^{\circ} \mathrm{C}$ pendant $5 \mathrm{~s}$ (Kiermeier et Vogt, 1956) ou dans du lait U.H.T. (Blanc, 1980) que l'enzyme est inactivée. Dans l'organisme, elle maintient une certaine activité lors du passage à l'estomac, malgré le milieu acide (Zikakis et al., 1977). Dans l'intestin grêle $20 \mathrm{ng}$ seulement sont résorbés sur $100 \mathrm{mg}$ de xanthine-oxydase présents dans du lait de vache frais. En outre, cette enzyme a une affinité plus grande avec la xanthine qu'avec les aldéhydes des acides gras (Ho et Clifford, 1976). Cependant, d'après les résultats scientifiques actuels, cette hypothèse doit être considérée comme invraisemblable (Renner, 1976, 1979). 


\section{Lactose-synthétase}

La lactose-synthétase (UDP galactose D-Glucose D-galactosyltransférase) catalyse le processus terminal de la biosynthèse du lactose (Brew et Hill, 1975) :

$$
\text { UDP-galactose + glucose } \rightarrow \text { lactose + UDP }
$$

La synthétase qu'on rencontre également dans le lait (Babad et Hassid, 1966) est un complexe de deux protéines, la protéine A et l'a-lactalbumine. En l'absence de l'a-lactalbumine, la protéine A qui apparaît aussi dans le lait (Brew, 1969), est une galactosyl-transférase qui catalyse la réaction suivante :

\section{UDP-galactose $+\mathrm{N}$-acétylglucosamine $\rightarrow$ $\mathrm{N}$-acétyl-lactosamine + UDP}

L'accepteur dans cette réaction peut être soit une N-acétylglucosamine libre, soit une glycoprotéine contenant une $\mathrm{N}$-acétylglucosamine, comme unité terminale de la chaîne latérale des oligosaccharides. La galactosyl-transférase est une glycoprotéine avec 330 restes d'acides aminés et 28 restes de sucres et un poids moléculaire de 42000 (Trayer et Hill, 1971). Selon Magee et al. (1973), le poids moléculaire est de 58000 . C'est par l'activité de la trypsine que l'enzyme est transformée en une forme entièrement active d'un poids moléculaire de 42000 , puis en une forme inactive d'un poids moléculaire de $38000.10,6 \mathrm{mg}$ de cette enzyme ont été isolés dans $23 \mathrm{l}$ de lait de vache en 3 à 4 semaines (Trayer et Hill, 1971). Au moyen de la chromatographie d'affinité, il est possible d'obtenir même $20 \mathrm{mg}$ de galactosyl-transférase d'un haut degré de pureté (Geren et al., 1976). La galactosyl-transférase est inactivée par des réactifs modifiant le sulfhydryle, mais la présence de UDP galactose et de $\mathrm{Mn}^{2+}$, ainsi que d'UDP et de $\mathrm{Mn}^{2+}$ protège cette enzyme contre l'inactivation par des réactifs tels que les $\mathrm{N}$-éthylmaléimides ou les p-chloromercuribenzoates. De même, le $\mathrm{Mn}^{2+}$ et le nucléotide empêchent la transformation de la forme active en inactive par la trypsine (Magee et Ebner, 1974). Le manganèse est donc un élément important pour l'activité de la galactosyl-transférase. Ainsi, le complexe ternaire de l'enzyme (enzyme. $\mathrm{Mn}^{2+}$. UDP gal) en provenance de lait bovin définitif comporte 2 atomes de manganèse (II) par molécule d'enzyme, alors que la galactosyl-transférase du colostrum bovin ne présente pas une spécificité absolue pour le $\mathrm{Mn}^{2+}$. Elle est activée par plusieurs ions métalliques, le $\mathrm{Ca}^{2+}$ surtout, qui sont liés à deux sites de l'enzyme (Andrée et Berliner, 1980 ; Powell et Brew, 1976 a). Le glucose est également un substrat de la galactosyl-transférase, mais son $\mathrm{K}_{\mathrm{s}}$ étant de $1 \mathrm{M}$ environ, il n'y a pas de formation de lactose lorsque le glucose se trouve à des concentrations physiologiques. Dans ces conditions, la synthèse du lactose n'a lieu que lorsque cette enzyme forme un complexe avec l'a-lactalbumine, car le $\mathrm{K}_{\mathrm{s}}$ du glucose est abaissé 1000 fois et la galactosyl-transférase est activée d'abord par le $\mathrm{Mn}^{2+}$. D'après Bell et al. (1976), l'addition de substrats au complexe enzyme. $\mathrm{Mn}^{2+}$ 
s'effectue par un "random equilibrium mechanismus ", et l'a-lactalbumine peut se lier soit au complexe enzyme. $\mathrm{Mn}^{2+}$. UDP galactose, soit au complexe enzyme. $\mathrm{Mn}^{2+}$. N acétyl-glucosamine ou glucose. Powell et Brew (1976 b), en revanche, postulent que pour la synthèse du lactose, l' $\alpha$-lactalbumine ou le glucose et ensuite les autres composants seraient liés au complexe enzyme. $\mathrm{Mn}^{2+}$. UDP galactose. Le produit peut se détacher soit du complexe enzyme. $\mathrm{Mn}^{2+}$. UDP galactose-glucose, soit du complexe enzyme. $\mathrm{Mn}^{2+}$. UDP galactoseglucose- $\alpha$-lactalbumine.

\section{HORMONES}

Chez la femelle des mammifères, la gestation et la parturition sont dirigées par des mécanismes de régulation neurohormonaux, associés directement au déclenchement de la production du lait. Diverses hormones sont transportées à partir des glandes endocrines, par voie sanguine, aux organes récepteurs. C'est grâce à des processus passifs de diffusion que les hormones parviennent au lait. Leur présence dans le lait est le résultat de l'équilibre physiologique entre leur concentration dans le sang, le liquide extra-cellulaire, les cellules épithéliales des mamelles et la sécrétion lactée. Les hormones produites par les mammifères se rangent parmi :

- les protéohormones et les hormones peptidiques : prolactine, hormones de lutéinisation ;

- les hormones stéroïdes : androgènes et corticoïdes, œstrogènes et gestagènes ;

- les prostaglandines.

Plusieurs revues ont été publiées sur la présence d'hormones dans le lait (Cowie et Swinburne, 1977 ; Hansel et al., 1976 ; Hoffmann, 1977 ; Koldovsky, 1980 ; Malven, 1977 ; Pope et Swinburne, 1980 ; Richardson et Mattarella, 1977).

Ce travail se limite à la discussion des protéohormones et des hormones peptidiques détectées jusqu'ici dans le lait. L'étude la plus approfondie a été consacrée à la prolactine (Malven, 1977).

\section{La prolactine}

La prolactine est une hormone de l'adénohypophyse et, conjointement avec d'autres hormones, elle joue un rôle important lors de la lactogenèse et pendant la lactation (Schams, 1974). Elle règle la synthèse des protéines lactiques : alpha-lactalbumine et caséine (Tucker, 1981). Dans le sang, elle est fortement influencée par une série de facteurs tels que stress, alimentation, stimuli provoqués par la traite ou l'allaitement.

Une certaine dépendance existe entre la teneur en prolactine du plasma sanguin et celle du lait. Des essais sur rates avec infusion 
de prolactine montrent que la prolactine passe rapidement du plasma au lait. L'importance de ce transfert est en relation directe avec la concentration de la prolactine dans le plasma : ainsi, une infusion de $200 \mathrm{ng} / \mathrm{min}$, après $5 \mathrm{~min}$, fait augmenter la teneur initiale en prolactine du lait d'environ $68 \mathrm{ng} / \mathrm{ml}$, et elle reste à ce niveau pendant une durée prolongée après la fin de l'infusion (Grosvenor et Whitworth, 1976). Pour la lapine, par contre, la quantité de prolactine transportée au lait est moins importante (Birkinshaw et Falconer, 1972). Chez les brebis, les truies et les vaches en lactation, les teneurs en prolactine du plasma sanguin et celles du lait sont à peu près identiques, à l'exception du colostrum bovin où la concentration en prolactine est 2 à 5 fois plus élevée que dans le plasma sanguin (Erb et al., 1977 a, b ; Keller et al., 1977 ; Mulloy et Malven, 1979). Après infusion de prolactine exogène, la concentration dans le lait augmente plus lentement chez les brebis que chez les rates : chez les brebis, la teneur du plasma augmente de $3,8 \mathrm{ng} / \mathrm{ml}$ avant l'infusion à $400 \mathrm{ng} / \mathrm{ml}$ 25 min après l'infusion et celle du lait de $19 \mathrm{ng} / \mathrm{ml}$ avant l'infusion à $42 \mathrm{ng} / \mathrm{ml} 90 \mathrm{~min}$ après l'infusion. L'élimination à $50 \%$ de l'hormone du plasma se fait en $60 \mathrm{~min}$ (McMurtry et Malven, $1974 \mathrm{~b}$ ). Chez la femme, la concentration de prolactine est à peu près 3 à 4 fois plus élevée que dans le lait (Gala et al., 1975).

Après séparation chromatographique sur colonne Séphadex G-100 la prolactine du lait maternel se présente presque exclusivement sous forme de composés de faible poids moléculaire (plus de $90 \%$ ), contrairement à celle du sérum humain, dans lequel se trouvent trois composants dans le volume d'exclusion, un à $13 \%$, l'autre à $26 \%$ et le troisième à $60 \%$ (Gala et Van de Walle, 1977). De même les laits de vache et de chèvre ne contiennent que les composés de faible poids moléculaire, alors que dans le sang on trouve la prolactine sous deux formes (Gala et al., 1980).

A l'aide des analyses radioimmunologiques, il est possible de détecter dans le lait de différents mammifères les taux de prolactine représentés dans la figure 5 à la page suivante. De nombreuses maisons spécialisées dans le domaine des réactifs de laboratoire pour la chimie clinique sont en train de développer des méthodes immunologico-enzymatiques des hormones (humaines spécialement). La présence de prolactine dans la matière grasse laitière bovine doit être considérée comme un artifice et de ce fait, le taux de cette hormone dans le lait entier est surestimé par les analyses radioimmunologiques à double anticorps de la prolactine (Gala, 1980). du lait.

Différents facteurs peuvent influencer la teneur en prolactine

\section{a) Période de lactation}

La teneur en prolactine du lait de vache s'accroît légèrement $7 \mathrm{j}$ et fortement $2 \mathrm{j}$ avant le vêlage ; elle atteint le maximum après la mise bas et s'abaisse à sa valeur initiale dans les 2 j 


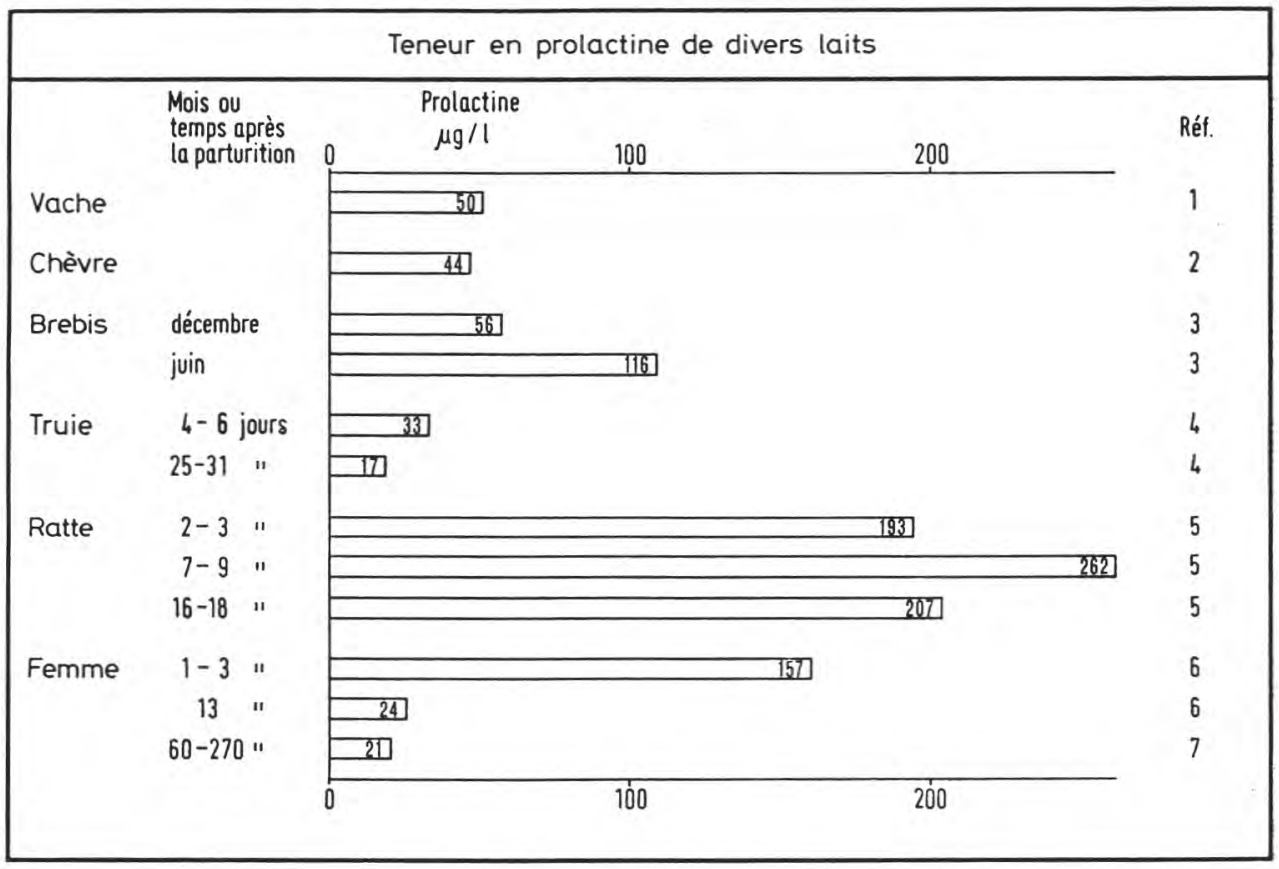

fig. 5

Teneur en prolactine du lait de différents mammifères (Références : 1. Mc Murtry et al., 1975 ; 2. Malven et McMurtry, 1974 ; 3. ERB et al., $1977 \mathrm{~b}$;

4. Mulloy et al., 1979 ; 5. McMurtry et al., 1974 a ; 6. Healy et al., 1980 ;

7. GaLA et al., 1975).

Prolactine content of milk from different species (from McMURTRY et al., 1975; Malven and McMurtry, 1974; Erb et al., 1977 b; Mulloy et al., 1979; McMurtry et al., 1974 a; Healy et al., 1980; Gala et al., 1975).

suivants. A la première traite après le vêlage, le taux de prolactine s'élève à $230 \mathrm{ng} / \mathrm{ml}$ et lors de la sixième traite, elle est de $23 \mathrm{ng} / \mathrm{ml}$ pour se maintenir par la suite à ce niveau (Schams et Schmidt-Polex, 1978).

Avec une moyenne de $24,9 \mathrm{ng} / \mathrm{ml}$ dans le $1^{\text {er }}$ mois de lactation, la teneur en prolactine du lait bovin écrémé est significativement plus élevée que pendant le $2^{\mathrm{e}}(18,9 \mathrm{ng} / \mathrm{ml})$ et les mois suivants (Beck et Turcker, 1977). D'après McMurtry et al. (1975), on observe une nette diminution de la teneur en prolactine du lait de vache, surtout au cours de la lactation ; la même tendance se note pour le lait de truie (Mulloy et Malven, 1979).

Dans le lait de femme, la concentration de prolactine est élevée pendant les 3 premiers jours après la naissance, soit $157 \pm 18 \mathrm{ng} / \mathrm{ml}$ 
le $3^{\mathrm{e}} \mathrm{j}$; elle s'abaisse à $24 \mathrm{ng} / \mathrm{ml} 13 \mathrm{j}$ après l'accouchement (Healy et al., 1980).

Dans le lait de rate, le taux de prolactine atteint un maximum entre le $4^{\mathrm{e}}$ et le $6^{\mathrm{e}} \mathrm{j}$ et se maintient à ce niveau jusqu'au $15^{\mathrm{e}} \mathrm{j}$ (McMurtry et Malven, 1974 a).

b) Saison

Dans le lait de vache, la concentration de prolactine augmente en avril, atteint le maximum en juillet et décroît ensuite jusqu'au mois de novembre (Schams et Schmidt-Polex, 1978).

D'après Beck et Tucker (1977), par contre, elle reste constante au cours de l'année dans du lait bovin écrémé.

Pour le lait de brebis, on constate des différences dans la teneur en prolactine entre été et automne (Erb et al., 1977 b).

c) Lait du matin et lait du soir

Chez la vache et la brebis, il n'existe pas de différences dans la teneur en prolactine entre le lait du matin et le lait du soir bien que la prolactine du plasma varie à un rythme de 24 et de 6 h (McMurtry) et Malven, 1974 b; Mollett et Malven, 1982; Schams et SchmidtPolex, 1978). Lorsque la traite est effectuée chaque heure, la teneur en prolactine du lait de brebis est significativement plus basse après 0 et 1 h qu'après 2, 3 et 4 h (Erb et al., 1977 b).

\section{d) Importance de la portée à la naissance}

Qu'une vache allaite un veau ou deux n'entraîne pas de différence statistiquement significative dans la teneur en prolactine du plasma, alors que dans le lait, les taux de prolactine sont différents, soit $334,1 \mathrm{ng} / \mathrm{ml}$ pour 2 veaux et $259,2 \mathrm{ng} / \mathrm{ml}$ pour 1 veau (Wheeler et al., 1982). Chez les rates et les truies, l'importance de la portée à la naissance influence la concentration de prolactine dans le lait (McMurtry et Malven, 1974 a ; Mulloy et Malven, 1979).

\section{e) Environnement}

Une analyse de régression multiple de 1316 échantillons de lait de vache révèle qu'un taux de prolactine accru est associé à des températures extrêmes (28० C et $-5^{\circ} \mathrm{C}$ ) (McMurtry et al., 1975).

\section{f) Influence d'autres hormones}

Une injection d'adrénocorticotrophine chez des vaches en lactation ne produit aucun changement dans la concentration de prolactine, ni dans le plasma ni dans le lait (Fox et al., 1981). En revanche, l'injection de thyrolibérine entraîne un accroissement énorme du taux de prolactine, particulièrement dans le sérum bovin, se prolongeant pendant 2 à $3 \mathrm{~h}$; dans le lait, un effet prononcé ne se produit qu'après application de $500 \mu \mathrm{g}$ de thyrolibérine (Schams et Schmidt-Polex, 1978). Chez les brebis, une seule injection de $3 \mathrm{mg}$ d'ergocryptine 
après la traite du matin réduit le taux de prolactine dans le lait du soir d'une valeur initiale de 25 à $11 \mathrm{ng} / \mathrm{ml}$.

Une infusion subséquente de TRF (thyrotrophin releasing factor) de 20 et de $50 \mu \mathrm{g}$ provoque dans le sang des pics respectivement de 70 à 80 et de 151 à $172 \mathrm{ng} / \mathrm{ml}$; dans le lait, on peut constater des augmentations significatives, soit de 2 à 15 et de 5 à $26 \mathrm{ng} / \mathrm{ml}$ de prolactine (McMurtry et Malven, 1974 b).

\section{Autres protéohormones et hormones peptidiques}

Dans quelques cas, la présence d'autres protéines à activité hormonale a été mise en évidence dans le lait de certains mammifères. Dans le lait de vache, on a détecté du lactogène placentaire ; celui-ci passe à raison de $86 \%$ du sérum au lait bovin au début du dernier trimestre de gestation, à savoir entre 350 et $680 \mathrm{ng} / \mathrm{ml}$. Cette hormone peut induire la formation de récepteurs de prolactine dans le tissu mammaire, qui réagit ainsi plus facilement à la prolactine après la naissance (Bolander et al., 1976).

Dans les laits de femme, de vache et de rate, on a détecté, à l'aide de tests radio-immunologiques, le GRF (gonadotrophin releasing factor) à une concentration de 0,5 à $3 \mathrm{ng} / \mathrm{ml}$. Ce peptide provient de l'hypothalamus et exerce une action hormonale chez des rats allaités (Baram et al., 1977). En outre, on peut isoler dans l'estomac de rats néonataux allaités par une mère, de la mélatonine, qui produit des effets antigonadotropes sur le système de reproduction en développement (Reppert et Klein, 1978). Outre le GRF, on rencontre dans le lait de femme, de vache et de rate, à une concentration encore plus basse, un deuxième peptide provenant de l'hypothalamus, le TRF (thyrotrophin releasing factor) (Baram et al., 1977). Comme signalé plus haut, ce facteur influence à son tour les taux sérique et lactique de prolactine. Les techniques radio-immunologiques permettent également de mettre en évidence l'hormone de croissance dans les laits de chèvre et de vache (Hart, cit. d'après Cowie et Swinburne, 1976).

D'après des résultats non publiés de Schams (cit. selon Hoffmann, 1976), il semble que l'hormone lutéotrope sécrétée par l'hypophyse est aussi présente dans le lait bovin. Dans le lait humain, on trouve le LRF (luteotrophin releasing factor) à une concentration 5 à 6 fois plus forte $(106,9 \pm 7,9 \mathrm{ng} / 1)$ que dans le plasma (Sarda et Nair, 1981).

\section{Importance des hormones dans le lait}

Physiologiquement, les hormones transportées par voie sanguine règlent les mécanismes de reproduction. Dans la glande mammaire, elles peuvent passer du sang au lait.

Le fait du passage des hormones au lait peut être utilisé à des fins diagnostiques lorsque les concentrations hormonales du lait et 
du sang sont proportionnelles. Cela a été prouvé clairement pour la prolactine, l'œstrone et la progestérone.

En pratique, ce n'est que le dosage de la progestérone dans le lait bovin qui a acquis une certaine importance pour le contrôle de la fertilité (Hoffmann, 1977; Pope et Swinburne, 1980).

Les protéohormones, grâce aux petites quantités présentes dans le lait de vache, ne constituent guère un risque pour le consommateur. La teneur en prolactine s'élève tout au plus à $0,0003 \%$ des protéines totales du lait (Malven et McMurtry, 1974). Ingérées par voie orale, elles sont décomposées dans les conditions du tractus gastro-intestinal. Il s'ensuit que l'intestin de rats nouveau-nés est perméable à la prolactine. Il est vrai que Malven et al. (1976) n'ont pas trouvé de prolactine provenant de lait dans le sang de rats âgés de 10 à $12 \mathrm{j}$ et de veaux âgés de 1 à $6 \mathrm{j}$. En revanche, Whitworth et Grosvenor (1978) constatent que la prolactine du lait de rate entre rapidement dans la circulation des jeunes rats allaités; après infusion de prolactine de rate marquée ${ }^{131} \mathrm{I}$ par tubage gastrique, les rats âgés de 9 à $14 \mathrm{j}$ ont de la prolactine dans le plasma, qui n'y est plus présente lorsque les animaux atteignent l'âge de $27 \mathrm{j}$ (Whitworth et Grosvenor, 1978). Mulloy et al. (1979) ont trouvé de la prolactine dans le sérum de rats âgés de 7 et de 8 j, 30 et 45 min après administration perorale de $400 \mathrm{ng}$ de prolactine bovine, alors qu'à l'âge de 9 et de $14 \mathrm{j}, 45 \mathrm{~min}$ après l'ingestion, cette hormone n'est plus décelable dans le sang des animaux. La prolactine du lait de vache et de chèvre a une activité biologique quand on l'applique sur une culture de glande mammaire d'une lapine artificiellement gestante. Ces deux observations seraient de nature à soulever l'hypothèse d'une fonction physiologique de la prolactine dans la biologie du nouveau-né (Gala et al., 1980).

\section{CONCLUSION}

Quelques 60 enzymes ont été décelées dans les laits des mammifères. Il est étonnant que, malgré cette multitude d'enzymes, le lait soit relativement stable. Cela doit être attribué aux nombreux facteurs régulateurs, neutralisants et inhibiteurs, à la structure physicochimique du lait, à la présence de membranes masquant les substrats et à l'absence de substrats appropriés à l'activité de certaines enzymes. Technologiquement les enzymes participent aux modifications de la qualité du lait ; ce sont des indicateurs de traitements thermiques que le lait a subis ou d'infections mammaires. Elles ont des propriétés antimicrobiennes, ce qui est essentiel pour l'alimentation du nouveau-né.

Parmi les protéohormones sécrétées dans le lait, la prolactine est la plus importante. D'après les résultats les plus récents, elle 
semble avoir une fonction physiologique dans la biologie $\mathrm{du}$ nouveau-né.

\section{Remerciements}

Je remercie $\mathrm{M} . \mathrm{R}$. Sieber pour son aide si précieuse lors de la préparation du présent travail.

\section{Bibliographie}

Aimutis (W. R.) and Eigel (W. N.) (1982). - Identification of $\lambda$-casein as plasminderived fragments of bovine $\alpha_{\mathrm{ss}_{1}}$-casein. J. Dairy Sci., $65,175-181$.

Alais (C.) and Blanc (B.) (1975). - Milk proteins: Biochemical and biological aspects. Wld Rev. Nutr. Diet., 20, 66-167.

AмmoN (R.) (1969). - Kommt den Nahrungsmittelfermenten eine Bedeutung für die Ernährung zu? Z. Ernährungswiss., Suppl. 8, 107-111.

ANDERSON (M.) (1977). - Source and significance of lysosomal enzymes in bovine milk fat globule membrane. J. Dairy Sci., 60, 1217-1222.

ANDERSON (M.) (1982). - Factors affecting the distribution of lipoprotein lipase activity between serum and casein micelles in bovine milk. J. Dairy Res., 49, 51-59.

Anderson (M.) and Cawston (T.E.) (1975). - Reviews of the progress of dairy science. The milk-fat globule membrane. J. Dairy Res., 42, 459-483.

ANdReE (P. J.) and BERLINer (L. J.) (1980). - Metal ion and substrate binding to bovine galactosyltransferase. Biochem., 19, 929-934.

ANDREWS (A. T.) (1978 a). - The composition, structure and origin of proteosepeptone component 5 of bovine milk. Eur. J. Biochem., 90, 59-66.

ANDREWS (A. T.) (1978 b). - The composition, structure and origin of proteosepeptone component $8 \mathrm{~F}$ of bovine milk. Eur. J. Biochem., 90, 67-75.

ANDREWS (P.) (1965). - The gel-filtration behaviour of proteins related to their molecular weights over a wide range. Biochem. J., 96, 595-606.

ARnold (C.) (1881). - Einige neue Reactionen der Milch. Arch. Pharm., 219, 41.

Arnold (R. G.), Shahni (K. M.) and Dwivedi (B. K.) (1975). - Application of lipolytic enzymes to flavor development in dairy products. J. Dairy Sci., 58, 1127-1143.

AsAdA (K.) (1976). - Occurrence of superoxide dismutase in bovine milk. Agr. Biol. Chem., 40, 1659-1660.

Aurand (L. W.), Boone (N. H.) and Giddings (G. G.) (1977). - Superoxide and singlet oxygen in milk lipid peroxidation. J, Dairy Sci., 60, 363-369.

BABAD (H.) and Hassid (Z.) (1966). - Soluble uridine diphosphate D-galactose: D-glucose $\beta$-4-D-galactosyltransferase from bovine milk. J. Biol. Chem., 241, 2672-2678.

Baram (T.), Koch (Y.), Hazum (E.) and FridKin (M.) (1977). - Gonadotropinreleasing hormone in milk. Science, 198, 300-302.

BARMAN (T.E.) and GutFreud (H.) (1966). - The catalytic-centre activity and kinetic properties of bovine milk alkaline phosphatase. Biochem. $J_{.}, 101$, $460-466$.

Baumrucker (C. R.) (1979). - $\gamma$-Glutamyl transpeptidase of bovine milk membranes: distribution and characterization. J. Dairy Sci., 62, 253-258. 
Beauchamp (C.) and Fridovich (L.) (1970). - Mechanism for the production of ethylene from methional. The generation of the hydroxyl radical by xanthine oxidase. J. Biol. Chem., 245, 4641-4646.

BECK (N. F. G.) and TUCKER (H. A.) (1977). - Relationships between radioimmunoassays of $\alpha$-lactalbumin and prolactin in bovine skim milk. J. Dairy Sci., $60,542-545$.

Belavady (B.) (1960), - Xanthine oxidase and alkaline phosphatase activity in the breast milk of poor Indian women. Indian J. Med. Res., 48, 654-660.

BElavady (B.) (1962). - Effect of protein supplementation to nursing mothers on some milk constituents: casein and xanthine oxidase. Indian J. Med. Res., 50, 100-103.

BeLl (J. E.), BEYER (T. A.) and Hill (R. L.) (1976). - The kinetic mechanism of bovine milk galactosyltransferase. The role of $\alpha$-lactalbumin. J. Biol. Chem., 251, 3003-3013.

BJorck (L.) (1982), - Activation of the lactoperoxidase system as a mean of preventing bacterial deterioration of raw milk. Kieler Milchwirt. Forschungsber., 34, 5-11.

Bjorck (L.), Claesson (O.) and Schulthess (W.) (1979). - The lactoperoxidase/ thiocyanate/hydrogen peroxide system as a temporary preservative for raw milk in developing countries. Milchwissenschaft, 34, 726-729.

BIRKINSHAW (M.) and FALCONER (I. R.) (1972). - The localization of prolactin labelled with radioactive iodine in rabbit mammary tissue. J. Endocrinol., $55,323-334$.

Blackberg (L.), Lombardo (D.), Hernell (O.), Guy (O.) and Olivecrona (T.) (1981). Bile salt-stimulated lipase in human milk and carboxyl ester hydrolase in pancreatic juice. Are they identical enzymes? FEBS-Lett., 136, 284-288.

Blanc (B.) (1980). - Einfluss der thermischen Behandlung auf die wichtigsten Milchinhaltsstoffe und auf den ernährungsphysiologischen Wert der Milch. Alimenta. Sonderausgabe, 5-25.

BLANC (B.) (1981). - Biochemical aspects of human milk. Comparison with bovine milk. Wld Rev. Nutr. Diet., 36, 1-89.

BoGIN (E.) and ZIV (G.) (1973). - Enzymes and minerals in normal and mastitic milk. Cornell Veterinarian, 63, 666-676.

Bogin (E.), ZIV (G.) and Avidar (J.) (1976), - Enzyme activities in normal and inflamed bovine udder tissues. Z $b l$. Vet. Med. A., 23, 460-466.

Bogin (E.), Ziv (G.), Avidar (J.), Rivetz (B.), Gordin (S.) and SARAN (A.) (1977). - Distribution of lactate dehydrogenase isoenzymes in normal and inflamed bovine udders and milk. Res. Vet. Sci., 22, 198-200.

Bolander (F. F.) Jr., Ulberg (L. C.) and Fellows (R. E.) (1976). - Circulating placental lactogen levels in dairy and beef cattle. Endocrinology, 99, 1273-1278.

BRAY (R. C.) (1975). - Molybdenum iron-sulfur flavin hydrolases and related enzymes. In «The Enzymes», Vol. XII, edited by Broyer P. D. F., Academic Press, New York.

BREW (K.) (1969). - Secretion of $\alpha$-lactalbumin into milk and its relevance to the organization and control of lactose synthetase. Nature, 222, 671-672.

Brouet-Yager (M.), Kleiner (H.), van Bogaert (E.) and GrafF (G. L. A.) (1974). L-Cystinyl-di- $\beta$-naphtylamide hydrolase ("oxytocinase») in human colostrum and early milk plasma. Separation of two isozymes by acrylamide gel electrophoresis. Clin. Chim. Acta, 54, 387-389.

BRown (W. H.) (1940). - Some of the factors affecting the phosphatase values of butter. J. Dairy Sci., 23, 510-511. 
BRUNNER (J.R.) (1981). - Cow milk proteins: twenty-five years of progress. J. Dairy Sci., 64, 1038-1054.

Bushway (A. A.) and KEENAN (T. W.) (1979). - Characterization of a soluble glycolipid galactosyltransferase which occurs in bovine milk. Biochim. Biophys. Acta, 572, 146-152.

CARLSTROM (A.) (1969). - Physical and compositional investigations of the subfractions of lactoperoxidase. Acta Chem. Scand., 23, 185-202.

Chandan (R. C.), Parry (R. M.) Jr. and Shahani (K. M.) (1965). - Purification and some properties of bovine milk lysozyme. Biochim. Biophys. Acta, 110, 389-398.

Chandan (R. C.), Parry (R. M.) Jr, and Shahani (K. M.) (1968). - Lysozyme, lipase, and ribonuclease in milk of various species. J. Dairy Sci., 51, 606-607.

Chilliard (Y.) (1982). - Variations physiologiques des activités lipasiques et de la lipolyse spontanée dans les laits de vache, de chèvre et de femme : revue bibliographique. Le Lait, 62, 1-31, 126-154.

Clamagirand-Mulet (C.), Badet (J.) and Cartron (J. P.) (1981). - Isoelectrofocusing pattern of $2-\alpha-\mathrm{L}, 3-\alpha-\mathrm{L}$ and $4-\alpha-\mathrm{L}$ fucosyltransferases from human milk and serum. FEBS-Lett., 126, 123-126.

Cowie (A. T.) and SwInburne (J. K.) (1977). - Hormones, drugs, metals and pesticides in milk: a guide to the literature. Dairy Sci. Abstr., 39, 391-402.

Demott (B. J.) and PRAepanitchai (O. A.) (1978). - Influence of storage, heat, and homogenization upon xanthine oxidase activity of milk. J. Dairy Sci., $61,164-167$.

Deodhar (A. D.), Rajalakshmi (R.) and Ramakrishnan (C. V.) (1964). - Studies on human lactation. IV. Lactic and malic dehydrogenase and xanthine oxidase in breast milk and their variation with the progress of lactation and dietary vitamin supplementation. Acta Paediat., 53, 101-104.

Downey (W. K.) and Murphy (R.F.) (1975). - Partitioning of the lipolytic enzymes in bovine milk. International Dairy Federation Annual Bulletin Document $86,19-23$.

DRIESSEN (F. M.) and VAN DER WAALS (C. B.) (1978). - Inactivation of native milk proteinase by heat treatment. Neth. Milk Dairy J., 32, 245-254.

EICHEL (V.) (1981). - Untersuchungen zur Bestimmung der Leuzinaminopeptidase in der Kuhmilch. Arch. exper. Vet. med., Leipzig, 35, 235-244.

EIGEL (W. N.) (1977). - Formation of $\gamma_{1}{ }^{{ }^{A} 2}, \gamma_{2}{ }^{{ }^{A} 2}$ and $\gamma_{3^{-}}$caseins by in vitro proteolysis of $\beta$-casein ${ }^{{ }^{A} 2}$ with bovine plasmin. Int. J. Biochem., 8, 187-192.

EIGEL (W. N.) (1981). - Identification of proteose peptone compound 5 as a plasmin derived fragment of bovine $\beta$-casein. Int. J. Biochem., 13, 1081.

Eigel (W. N.), Hofmann (C. J.), Chibber (B. A. K.), Tomich (J. M.), Keenan (T. W.) and Mertz (E. T.) (1979). - Plasmin-mediated proteolysis of casein in bovine milk. Proc. Nat. Acad. Sci. U.S.A., 76, 2244-2248.

Eigel (W. N.) and KEENAN (T. N.) (1979). - Identification of proteose peptone compound 8-slow as a plasmin-derived fragment of bovine $\beta$-casein. Int. J. Biochem., 10, 529.

Eitenmiller (R. R.), Friend (B. A.) and Shahani (K. M.) (1976). - Relationship between composition and stability of bovine milk lysozyme. J. Dairy Sci, $59,834-839$.

Erb (R. E.), Chew (B. P.), Keller (H. F.) and Malven (P. V.) (1977 a). - Effect of hormonal treatments prior to lactation on hormones in blood plasma, milk, and urine during early lactation. J. Dairy Sci., 60, 557-565.

Erb (R. E.), Sitarz (N.E.) and Malven (P. V.) (1977 b). - Blood plasma and milk prolactin, and effects of sampling technique on composition of milk from suckled ewes. J. Dairy Sci., 60, 197-203. 
ERIKSSON (C. E.), (1970). - Nonenzymatic lipid oxidation by lactoperoxidase. Effect of heat treatment. J. Dairy Sci., 53, 1649-1653.

ERWin (R. E.) and RANDoLPH (H. E.) (1975). - Influence of mastitis on properties of milk. XI. Fat globule membrane. J. Dairy Sci., 58, 9-12.

Fitz-Gerald (C. H.), Deeth (H. C.) and Kitchen (B. J.) (1981). - The relationship between the levels of free fatty acids, lipoprotein lipase, carboxylesterase, $\mathrm{N}$-acetyl- $\beta$-D-glucosaminidase, somatic cell count and other mastitis indices in bovine milk. I. Dairy Res., 48, 253-265.

FoX (L.), Butler (W.R.), Everett (R. W.) and NATZKe (R. P.) (1981). - Effect of adrenocorticotropin on milk and plasma cortisol and prolactin concentrations. J. Dairy Sci., 64, 1794-1803.

Fox (P. F.) (1981). - Proteinases in dairy technology. Neth. Milk Dairy J., 35, 233-253.

FOX (P. F.) and MORRISSEY (P. A.) (1981). - Indigenous enzymes of bovine milk. In "Enzymes and food processing», edited by Birch G. G., Blakebrough N., Parker K. J., Applied Science Publ., London.

FrAM (H.) (1957). - The reactivation of phosphatase in H.T.S.T. pasteurized dairy products. J. Dairy Sci., 40, 19-27.

GaLA (R. R.) (1980). - Cow milk fat interferes with prolactin radioimmunoassay. Life Sci., 26, 783-788.

GalA (R. R.), Forsyth (I. A.) and TURVeY (A.) (1980) - - Milk prolactin is biologically active. Life Sci., 26, 987-993.

Gala (R. R.), Singhakowinta (A.) and Brennan (M. J.) (1975). - Studies on prolactin in human serum, urine and milk. Hormone Res., 6, 310-320.

Gala (R. R.) and VAN DE WALLE (C.) (1977). - Prolactin heterogeneity in the serum and milk during lactation. Life Sci., 21, 99-104.

GED (J.) et Alais (C.) (1976). - Etude de la réactivation de la phosphatase alcaline dans le lait stérilisé par friction. Le Lait, 56, 407-413.

Geren (C. R.), Magee (S. C.) and Ebner (K. E.) (1976). - Hydrophobic chromatography of galactosyltransferase. Arch. Biochem. Biophys., 172, 149-155.

Got (R.) (1971), - Les enzymes des laits. Ann. Nutr. Alim., 25, A 291-A 311.

GrosvenoR (C. E.) and WHITWORTH (N. S.) (1976). - Incorporation of rat prolaclactin into rat milk in vivo and in vitro. $J$. Endocrinol., $70,1-9$.

GRoves (M. L.) (1971). - Minor milk proteins and enzymes. In «Milk proteins», Vol. II, edited by Mc Kenzie (H. A.), Academic Press, New York and London.

Hanafy (M. M.), El-Khateeb (S.), Guiris (F. K.) and El-Lozy (M.) (1971). Diastase in human milk. Alex. Med. J., 17, 299-305. (Dairy Sci. Abstr., 1972, $34,491)$.

Hansel (W.), Hixon (J.), Shemesh (M.) and Tobey (D.) (1976). - Concentrations and activities of prostaglandins of the $\mathrm{F}$ series in bovine tissue, blood, and milk. J. Dairy Sci., 59, 1353-1365.

Harnulv (B. G.) and Kandasamy (C.) (1982). - Possibilities to utilize the lactoperoxidase system in tropical countries to save milk from an early spoilage. Kieler Milchwirt. Forschungsber., 34, 47-50.

HARPAZ (N.) and SchachteR (H.) (1980). - Control of glycoprotein synthesis. Bovine colostrum UDP-N-acetylglucosamine: $\alpha$-D-mannoside $\beta 2-\mathrm{N}$-acetylglucosaminyltransferase. I. Separation from UDP-N-acetylglucosamine: $\alpha$-D-mannoside $\beta 2$-N-acetylglucosaminyltransferase. II. Partial, purification and substrate specificity. J. Biol. Chem., 255, 4885-4893.

Hart (L. I.), Owen (E. C.) and Proudfoot (R.) (1967). - The influence of dietary molybdenum on the xanthine oxidase activity of the milk of ruminants. $B r$. J. Nutr., 21, 617-630. 
Healy (D. L.), Rattigan (S.), Hartmann (P. E.), Herington (A. C.) and Burger (H. G.) (1980). - Prolactin in human milk: correlation with lactose, total protein, and $\alpha$-lactalbumin levels. Am. J. Physiol., 238, E 83-E 86.

Hernell (O.) and Olivecrona (T.) (1974 a). - Human milk lipases. I. Serumstimulated lipase. J. Lipid Res,, 15, 367-374.

Hernel. (O.) and Olivecrona (T.) (1974 b). - Human milk lipases. II. Bile saltstimulated lipase. Biochim. Biophys. Acta, 369, 234-244.

Hicks (C. L.) (1980). - Occurrence and consequence of superoxide dismutase in milk products: a review. J. Dairy Sci., 63, 1199-1204.

Hicks (C. L.), Bucy (J.) and Stofer (W.) (1979). - Heat inactivation of superoxide dismutase in bovine milk. J. Dairy Sci., 62, 529-532.

Hicks (C. L.), Korycka-Dahl (M.) and Richardson (T.) (1975). - Superoxide dismutase in bovine milk. J. Dairy Sci., 58, 796.

Hill (R. D.) (1975). - Superoxide dismutase activity in bovine milk. Aust. J. Dairy Technol., 30, 26-28.

Hill (R. D.) (1977). - The catalysis of the oxidation of epinephrine by lactoperoxidase. New Zeal. J. Dairy Sci. Technol., 12, 37-43.

Hill (R. L.) and BREw (K.) (1975). - Lactose synthetase. Adv. Enzymol. Relat. Areas Molec. Biology, 43, 411-490.

Ho (C. Y.) and CLIFFORD (A. J.) (1976). - Digestion and absorption of bovine milk xanthine oxidase and its role as an aldehyde oxidase. J. Nutr., 106, 1600-1609.

HofFmann (B.) (1977). - Vorkommen und Bedeutung von Hormonen in der Milch. Milchwissenschaft, 32, 477-482.

HofmanN (C. J.), KeEnan (T.W.) and Eigel (W. N.) (1979). - Association of plasminogen with bovine milk fat globule membrane. Int. J. Biochem., 10, 909-917.

HoLBRooK (J.) and Hicks (C. L.) (1978). - Variation of superoxide dismutase in bovine milk. J. Dairy Sci., 61, 1072-1077.

Humbert (G.) and Alais (C.) (1979). - Review of the progress of Dairy Science: The milk proteinase system. J. Dairy Res., 46, 559-571.

JANOLINO (V. G.) and SWAISGOOD (H. E.) (1975). - Isolation and characterization of sulfhydryl oxidase from bovine milk. J. Biol. Chem., 250, 2532-2538.

JAUREGUI-ADELL (J.) (1975). - Heat stability and reactivation of mare milk lysozyme. J. Dairy Sci., 58, 835-838.

Jenness (R.) (1974). - The composition of milk. In «Lactation», Vol. III, edited by Larson B. L., Smith V. R., Academic Press, New York and London.

Jenness (R.) and Patton (S.) (1967). - Grundzüge der Milchchemie. Bayerischer Landwirtschaftsverlag, München, Basel, Wien.

Jensen (R. G.) and Pitas (R. E.) (1976). - Milk lipoprotein lipases: a review. J. Dairy Sci., 59, 1203-1214.

IWAMI (K.) FUSHIKI (T.), YASUMoto (K.) and IWAI (K.) (1981). - Glutathione oxidase from bovine skim milk membranes: its copurification with $\gamma$-glutamyltransferase. Agr. Biol. Chem., 45, 307-308.

Kaminogawa (S.), Mizobuchi (H.) and Yamauchi (K.) (1972). - Comparison of bovine milk protease with plasmin. Agr. Biol. Chem., 36, 2163-2167.

Kaminogawa (S.) and Yamauchi (K.) (1972). - Acid protease of bovine milk. Agr. Biol. Chem., 36, 2351-2356.

Kantor (J. A.), LeE (Y. H.), Churikjian (J. G.) and Feller (W. F.) (1979), - DNA polymerase with characteristics of reverse transcriptase purified from human milk. Science, 204, 511-513. 
Karmarkar (M. G.) and RAMAKRishnan (C. V.) (1959). - Relation between dietary fat, fat content of milk and concentration of certain enzymes in human milk. J. Nutr., 69, 274-276.

Karmarkar (M. G.), Rajalakshmi (R.) and Ramakrishnan (C. V.) (1963). - Studies of human lactation. II. Activities of certain milk enzymes in relation to dietary fat intake. Acta Paediat., 52, 554-556.

KEENAN (T. W.) (1974). - Membranes of mammary gland. IX. Concentration of glycosphingolipid galactosyl and sialyltransferases in Golgi apparatus from bovine mammary gland. J. Dairy Sci., 57, 187-192.

KeEnan (T. W.) and Huang (C. M.) (1972). - Membranes of mammary gland. IV. Glycosidase activity of milk fat globule membranes. J. Dairy Sci., 55, 1013-1015.

Keenan (T. W), Morre (D. J.) and Huang (C. M.) (1974). - Membranes of the mammary gland. In "Lactation", Vol. II, edited by Larson B. L., Smith V. R., Academic Press, New York and London.

Keller (H. R.), Chew (B. P.), Erb (R. E.) and Malven (P. V.) (1977). - Mammary transfer of hormones and constituents into secretions when cows were milked or secretions were sampled prepartum. J. Dairy Sci., 60, 546-556.

Kellogg (E. W.) III and Fridovich (I.) (1975). - Superoxide, hydrogen peroxide and singlet oxygen in lipid peroxidation by a xanthine oxidase system. J. Biol. Chem., 250, 8812-8817.

Kiermeier (F.) und CaPellari (K.) (1957). - Beeinflussung des XanthindehydraseGehaltes der Kuhmilch durch den Molybdängehalt des Futters. Naturwissenschaften, 44, 69.

KIERMEIER (F.) und DoRUK (M.) (1972). - Zur Hitzeinaktivierung der $\beta$-Glucuronidase in Milch. Z. Lebensm. Unters. Forsch., 150, $220-224$.

Kiermeier (F.) und Gull (J.) (1968). - Biologische Einflüsse auf die $\beta$-Glucuronidase-Aktivität der Milch. Z. Lebensm. Unters. Forsch., 138, 205-208.

Kiermeier (F.) und KuHLmanN (H.) (1972 a). - Laktoperoxidase-Aktivität in Human- und Kuhmilch. Vergleichende Untersuchungen. Münch. med. Wschr., $114,2144-2146$.

KieRmeier (F.) und KuHLMANN (H.) (1972 b). - Beeinflussung der Lactoperoxydase-Aktivität der Milch durch Euterentzündung. 7. Mitteilung. Z. Lebensm. Unters. Forsch., 150, 224-228.

KIERMEIER (F.) und MEINL (E.) (1961). - Zur Kenntnis der Milchphosphatasen. II. Verhalten der sauren Phosphatase neben der alkalischen in Kuhmilch. Z. Lebensm. Unters. Forsch., 114, 189-202.

Kiermeier (F.) und Petz (E.) (1967). - Ueber ein sulfhydrylgruppenoxydierendes Enzym in der Milch. I. Mitteilung. Isolierung und Charakterisierung des Enzyms. Z. Lebensm. Unters. Forsch, 132, 342-352.

Kiermeier (F.) und Vogt (K.) (1956 a). - Einfluss der Erhitzung auf die Xanthindehydrase der Milch. Z. Lebensm. Unters. Forsch., 103, 198-211.

KIERMEIER (F.) und VOGT (K.) (1956 b). - Ursachen unterschiedlicher Xanthindehydrase-Aktivität in Kuhmilch aus verschiedenen Anlieferugsbezirken. $Z$. Lebensm. Unters. Forsch., 103, 355-361.

KITCHEN (B. J.) (1974). - A comparison of the properties of membranes isolated from bovine skim milk and cream. Biochim. Biophys. Acta, 356, 257-269.

KITCHEN (B. J.) (1976). - Enzymic methods for estimation of the somatic cell count in bovine milk. I. Development of assay techniques and a study of their usefulness in evaluating the somatic cell content of milk. $J$. Dairy Res., 43, 251-258. 
Kitchen (B. J.), Middleton (G.), Durward (I. G.), Andrews (R. J.) and Salmon (M. C.) (1980). - Mastitis diagnostic tests to estimate mammary gland epithelial cell damage. J. Dairy Sci., 63, 978-983.

Kitchen (B. J.), Middleton (G.) and Salmon (M.) (1978). - Bovine milk N-acetyl$\beta$-D-glucosaminidase and its significance in the detection of abnormal udder secretions. J. Dairy Res., 45, 15-20.

Kitchen (B. J.), Taylor (G. C.) and White (I. C.) (1970). - Milk enzymes - their distribution and activity. I. Dairy Res., 37, 279-288.

Koldovsky (O.) (1980). - Hormones in milk. Life Sci., 26, 1833-1836.

KoRycKa-DaHL (M. B.) and Richardson (T.) (1978). - Photogeneration of superoxide anion in serum of bovine milk and in model systems containing riboflavin and amino acids. J. Dairy Sci., 61, 400-407.

KORYCKa-DAHL (M. B.) and RichaRDSON (T.) (1979). - Photogeneration of superoxide anion upon illumination of bovine milk serum proteins with fluorescent light in the presence of riboflavin. J. Dairy Sci., 62, 183-188.

Korycka-Dahl (M.), Richardson (T.) and Hicks (C. L.) (1979). - Superoxide dismutase activity in bovine milk serum. J. Food Protect., 42, 867-871.

KRESHECK (G. C.) and HARPER (W. J.) (1967). - Interpretation of the milk alkaline phosphatase reactivation process. Milchwissenschaft, 22, 72-75.

LANDON (M.) (1975). - $\alpha$-Glutamyltransferase in breast milk. Ann. Clin. Biochem., $12,48-50$.

LASKowSKi (M.), Kassell (B.) and Hagerty (G.) (1957), - A crystalline trypsin inhibitor from swine colostrum. Biochim. Biophys. Acta, 24, 300-305.

LASKOWSKI (M.) Jr. and LASKowsKI (M.) (1951). - Crystalline trypsin inhitor from colostrum. J. Biol. Chem., 190, 563-573.

Law (B. A.) (1979). - Reviews of the progress of Dairy Science: Enzymes of psychrotrophic bacteria and their effects on milk and milk products. J. Dairy Res., 46, 573-588.

Lindberg (T.) (1979). - Protease inhibitors in human milk. Pediat. Res., 13, 969-972.

LINDEN (G.) (1979). - Biochemical study of some aspects of milk alkaline phosphatase reactivation. Milchwissenschaft, 34, 329-332.

LINDEN (G.) et AlAIs (C.) (1976). - Phosphatase alcaline du lait de vache. II. Structure sous-unitaire, nature métalloprotéique et paramètres cinétiques. Biochim. Biophys. Acta, 429, 205-213.

Linden (G.), Chappelett-Tordo (D.) and Lazdunski (M.) (1977). - Milk alkaline phosphatase. Stimulation by $\mathrm{Mg}^{2+}$ and properties of the $\mathrm{Mg}^{2+}$ site. Biochim. Biophys. Acta, 483, 100-106.

LINDEN (G.) et GED (J.) (1976). - Activité, polymorphisme et origine de la phosphatase alcaline dans le lait. Milchwissenschaft, 31, 724-728.

Linden (G.), Mazeron (P.), Michalowski (J.B.) et Alais (C.) (1974). - Phosphatase alcaline du lait de vache. I. Purification et propriétés moléculaires. Biochim. Biophys. Acta, 358, 82-90.

Linden (G.) and PAouet (D.) (1981). - Alkaline phosphatase activity in transparent milk and cream. J. Dairy Sci., 64, 568-571.

LoRIENT (D.) and LINDEN (G.) (1976). - Dephosphorylation of bovine casein by milk alkaline phosphatase. J. Dairy Res., 43, 19-26.

LySTER (R. L. J.) and AschafFenburg (R.) (1962). - The reactivation of milk alkaline phosphatase after heat treatment. J. Dairy Res., 29, 21-35.

Magee (S. C.) and EbNer (K. E.) (1974). - Inactivation of soluble bovine milk galactosyltransferase (lactose synthetase) by sulfhydryl reagents and trypsin. Protection by substrates and products. J. Biol. Chem., 249, 6992-6998. 
Magee (S. C.), Geren (C. R.) and Ebner (K. E.) (1976). — Plasmin and the conversion of the molecular forms of bovine milk galactosyltransferase. Biochim. Biophys. Acta, 420, 187-194.

Magee (S. C.), Mawal (R.) and EbNer (K. E.) (1973). - Proteolytic conversion of the molecular forms of bovine milk galactosyltransferase. J. Biol. Chem., 248, $7565-7569$.

Magee (S. C.), Mawal (R.) and EbneR (K. E.) (1974). - Multiple forms of galactosyltransferase from bovine milk. Biochemistry, 13, 99-102.

Majumder (G. C.) and Ganguli (N. C.) (1972 a). - $\gamma$-Glutamyl transpeptidase in milk. I. Certain parameters influencing its activity. Milchwissenschaft, 27, 296-299.

Majumder (G. C.) and Ganguli (N. C.) (1972 b). - $\gamma$-Glutamyl transpeptidase in milk. I. Distribution in milk fractions. Milchwissenschaft, 27, 426-429.

Malven (P. V.) (1977). - Prolactin and other protein hormones in milk. J. Anim. Sci., 45, 609-616.

Malven (P. V.), Hollister (A. M.) and Morningstar (J. E.) (1976). - Failure to demonstrate transfer of milk prolactin into blood of milk-fed rats and calves. J. Dairy Sci., 59, 889-893.

Malven (P. V.) and McMurtRy (J. P.) (1974). - Measurement of prolactin in milk by radioimmunoassay. $J$. Dairy Sci., 57, 411-415.

Marquardt (R. R.), Forster (T. L.), Spencer (G. R.) and Stabenfeldt (G. H.) (1966). - A-Esterase activities of milk from cows with experimentally induced mastitis. $J$. Dairy Sci., 49, 631-635.

Mather (I. H.) and Keenan (T. W.) (1974). - The stability of alkaline phosphatase in sodium dodecyl sulfate. FEBS-Lett., 44, 79-82.

McMurtry (J. P.) and Malven (P. V.) (1974 a). - Radioimmunoassay of endogenous and exogenous prolactin in milk of rats. J. Endocrinol., 61, 211-217.

McMurtry (J.P.) and Malven (P. V.) (1974 b). - Experimental alterations of prolactin levels in goat milk and blood plasma. Endocrinology, 95, 559-564.

McMurtry (J.P.), Malven (P. V.), Arave (C. W.), Erb (R. E.) and Harrington (R. B.) (1975). - Environmental and lactational variables affecting prolactin concentrations in bovine milk. J. Dairy Sci., 58, 181-189.

MeYer (F.) und SenFt (B.) (1979). - Untersuchungen über Konzentrationsveränderungen der Molkenproteine Lactoferrin, Blut-Serum-Albumin und Lysozym im Verlauf des Milchentzuges. Milchwissenschaft, 34, 74-77.

Michelson (A. M.), McCord (J. M.) and Fridovich (I.) (1977). - Superoxide and superoxide dismutases. Academic Press, New York.

Mollett (T. A.) and Malven (P. V.) (1982), - Chronological profiles of prolactin and growth hormone in lactating cows. J. Dairy Sci., 65, 211-216.

Monget (D.) et Laviolette (P.) (1978). - Mise au point de microtests * phosphatase alcaline » et "peroxydase " pour le contrôle de la pasteurisation du lait de vache. Le Lait, 58, 595-605.

Morrison (M.) and ALLEN (P. Z) (1963). - The identification and isolation of lactoperoxidase from salivary gland. Biochem. Biophys. Res. Commun., 13, 490-494.

Morrison (M.), Allen (P. Z.), Bright (J.) and JAyasinghe (W.) (1965). - Lactoperoxidase. V. Identification and isolation of lactoperoxidase from salivary gland. Arch. Biochem. Biophys., 111, 126-133.

MotTAR (J.) (1981). - Heat resistant enzymes in UHT milk and their influence on sensoric changes during uncooled storage. Milchwissenschaft, 36, 87-91.

Mulloy (A. L.), KeEN (S. J.) and Malven (P. V.) (1979). - Absorption of orally administered bovine prolactin by neonatal rats. Biology Neonate, 36, 148-153. 
Mulloy (A. L.) and Malven (P. V.) (1979). - Relationships between concentrations of porcine prolactin in blood serum and milk of lactating sows. J. Anim. Sci., 48, 876-881.

MuRthy (G. K.), CoX (S.) and KAYLoR (L.) (1976). - Reactivation of alkaline phosphatase in ultra high-temperature short-time processed liquid milk products. J. Dairy Sci., 59, 1699-1710.

Murthy (G. K.), Martin (R.), Rhea (U. S.) and Peeler (J. T.) (1979). - Rapid colorimetric test for alkaline phosphatase in dairy products. J. Food Protect., 42, 794-799.

Ngoc-Du (D), Lenotr (J.) et Veisseyre (R.) (1965). - Contribution à l'étude des conditions de la réactivation de la phosphatase alcaline dans les crèmes pasteurisées. Le Lait, 45, 387-412.

Olivecrona (T.) and Hernell (O.) (1976). - Human milk lipases and their possible role in fat digestion. Pädiatrie Pädologie, 11, 600-604.

OSTER (K. A.) (1974). - Bovine milk xanthine oxidase as one of the dietary causes of early atherosclerosis. Med. Counterpoint, 6, 39-42.

Pahud (J. J.) and Widmer (F.) (1982). - Calf rennet lysozyme. Biochem. J., 201, 661-664.

Parry (R. M.) Jr., Chandan (R. C.) and Shahani (K. M.) (1969). - Isolation and characterization of human milk lysozyme. Arch. Biochem. Biophys., 130, 59-65.

PASCHKE (B.) (1953). - Nachweismethoden der Erhitzung von Trinkmilch in der Lebensmittelkontrolle. Milchwissenschaft, 8, 266-268.

PaschKe (B.) (1958), - Regeneration der Phosphatase. Milchwissenschaft, 13, 73-75.

Patton (S.) and KeEnAN (T.W.) (1975). - The milk fat globule membrane. Biochim. Biophys. Acta, 415, 273-309.

Paul (K. G.), Ohlsson (P. I.) and Hendriksson (A.) (1980). - The isolation and some liganding properties of lactoperoxidase. FEBS-Lett., 110, 200-204.

Paulson (J. C.), BeraneK (W. E.) and Hill (R. L.) (1977). - Purification of a sialyltransferase from bovine colostrum by affinity chromatography on CDP-agarose. J. Biol. Chem., 252, 2356-2362.

PEderson (T. C.) and Aust (S. D.) (1973). - The role of superoxide and singlet oxygen in lipid peroxidation promoted by xanthine oxidase. Biochem. Biophys. Res. Commun., 52, 1071.

Peereboom (J. W. C.) (1970). - Studies on alkaline milk phosphatase. III. A theory for the mechanism of reactivation of alkaline milk phosphatase in a model system. Fette. Seifen. Anstrichm., 72, 299-308.

PoPe (G. S.) and Swinburne (J. K.) (1980). - Reviews of the progress of Dairy Science: Hormones in milk: their physiological significance and value as diagnostic aids. J. Dairy Res., 47, 427-449.

Powell (J. T.) and BREW (K.) (1976 a), - Metal ion activation of galactosyltransferase. J. Biol. Chem., 251, 3645-3652.

PowELL (J. T.) and BREW (K.) (1976 b). - A comparison of the interactions of galactosyltransferase with a glycoprotein substrate (ovalbumin) and with a-lactalbumin. J. Biol. Chem., 251, 3653-3663.

Reimerdes (E. H.), HalpaAp (I.) und Klostermeyer (H.) (1981 a). - Milchproteinasen. 8. Vergleichende Charakterisierung von Plasmin aus Rinderblut mit. einer Serinproteinase aus Kuhmilch. Milchwissenschaft, 36, 19-22.

Reimerdes (E. H.), HalpaAp (I.) und Klostermeyer (H.) (1981 b). - Milchproteinasen. 10. Enzymkinetischer Vergleich bei Rinderplasmin mit zwei Milchproteinasen. Milchwissenschaft, 36, 73-79. 
REITER (B.) (1978). - Review of the progress of Dairy Science: antimicrobial systems in milk. J. Dairy Res., 45, 131-147.

REITER (B.) and HARnulv (B. G.) (1982). - Lactoperoxidase/thiocyanate/hydrogen peroxide - a natural antibacterial system. Kieler Michwirt. Forschungsber., $34,50-53$.

RENNER (E.) (1976). - Zur Kontroverse über die homogenisierte Milch. Dt. Milchwirt., 27, 560-562.

RENNER (E.) (1979). - Ist die homogenisierte Milch gesundheitsschädlich? Dt. Med. Wschr., 104, 45-46.

RepreRt (S. M.) and KLEIN (D. C.) (1978). - Transport of maternal ( $\left.{ }^{3} \mathrm{H}\right)$ melatonin to suckling rats and the fate of $\left({ }^{3} \mathrm{H}\right)$ melatonin in the neonatal rat. Endocrinology, $102,582-587$.

Richardson (T.) and MatTARella (N.) (1977), - Hormonal substances in human milk, cow's milk and dairy products. J. Food Protect., 40, 57-64.

RitTER (W.) (1949). - Der Nachweis der Pasteurisation von Milch und Milchprodukten durch die Phosphatasereaktion. Mitt. Gebiete Lebensm. Hyg., 40, 43-59.

SARDA (A. K.) and NAIR (R. M. G.) (1981). - Elevated levels of LRH in human milk. J. Clin. Endocrinol. Metab., 52, 826-828.

Schams (D.) (1974). - Untersuchungen über Prolaktin beim Rind. Fortschritte in der Tierphysiologie und Tierernährung. Heft 5, Verlag Paul Parey, Hamburg und Berlin.

Schams (D.) and Schmidt-Polex (B.) (1978). - Usefulness of radioimmunological determination of bovine prolactin in milk. Milchwissenschaft, 33, 418-421.

Schauer (R.), VeH (R. W.), Wember (M.) and Buscher (H. P.) (1976). - Demonstration of neuraminidase activity in human blood serum and human milk using a modified, radioactively labelled $\alpha_{1}$-glycoprotein as substrate. Hoppe Seyler's Z. Physiol. Chem., 357, 559-566.

Schultz (L. H.) (1977). - Somatic cells in milk - physiological aspects and relationship to amount and composition of milk. J. Food Protect., 40, 125-131.

Shahani (K. M.) (1966). - Milk enzymes: their role and significance. J. Dairy Sci., 49, 907-920.

Shahani (K. M.), Harper (W. J.), Jensen (R. G.), Parry (R. M.) Jr. and Zittle (C. A.) (1973). - Enzymes in bovine milk: a review. J. Dairy Sci., 56, 531-543.

SHAHANi (K. M.), KWAN (A. J.) and Fried (B. A.) (1980). - Role and significance of enzymes in human milk. Am. J. Clin. Nutr., 33, 1861-1868.

Sharma (R. S.) and Ganguli (N. C.) (1971). - Distribution pattern of certain enzymes in buffalo milk. Enzymologia, 40, 337-344.

SHARMA (R. S.) and GANGULI (N. C.) (1974). - Some observation on the reactivation of alkaline phosphatase of buffalo milk. Milchwissenschaft, 29, 408-412.

Shipe (W. F.), LeE (E. C.) and SenYK (G. F.) (1975). - Enzymatic modification of milk flavor. J. Dairy Sci., 58, 1123-1126.

SiegenthaleR (E.) (1954). - Reaktivierte Phosphatase in hochpasteurisiertem Schlagrahm und deren Nachweis. Mitt. Gebiete Lebensm. Unters. Hyg., 45, 84-92.

SIEVERS (G.) (1979). - The prosthetic group of milk lactoperoxidase is protoheme IX. Biochim. Biophys. Acta., 579, 181-190.

SIEvers (G.) (1980). - Structure of milk lactoperoxidase. A study using circular dichroism and difference absorption spectroscopy. Biochim. Biophys. Acta, 624, 249-259. 
SIEvers (G.) (1981). - Structure of milk lactoperoxidase. Evidence for a single polypeptide chain. FEBS-Lett., 127, 253-256.

Signer (E.), Murphy (G. M.), EdKins (S.) and ANDERSON (C. M.) (1974). - Role of bile salts in fat malabsorption of premature infants. Arch. Dis. Childhood, $49,174-180$.

Sklavunu-Zurukzoglu (S.), Mameletzis (C.) and Katriu (D.) (1965). - Observations on the glucose-6-phosphate dehydrogenase of the breast milk. Helv. Paediat. Acta, 20, 193-196.

Sliwkowski (M. B.), SLiwkowski (M.X.), Swaisgood (H. E.) and Horton (H. R.) (1981). - Nonidentity of sulfhydryl oxidase and $\gamma$-glutamyltransferase in bovine milk. Arch. Biochem. Biophys., 211, 731-737.

SOMMER (H.) und SONNECK (R.) (1980), - Beziehungen zwischen dem Zellgehalt der Kuhmilch und den Aktivitäten der Enzyme LDH und a-HBDH. Berl. Münch. Tierärztl. Wschr., 93, 84-86.

Stadhouders (J.) (1975). - Microbes in milk and dairy products. An ecological approach. Neth. Milk Dairy J., 29, 104-126.

Stannard (D. J.) (1975). - The use of marker enzymes to assay the churning of milk. J. Dairy Res., 42, 241-246.

Storrs (A. B.) and Hull (M. E.) (1956). - Proteolytic enzymes in human and cow's milk. J. Dairy Sci., 39, 1097-1103.

TKadlecova (M.) und Hanus (J.) (1973). - Das Vorkommen von Enzymen in Kuhmilch. Nahrung, 17, 565-577.

TRAYer (I. P.) and Hill (R. L.) (1971). - The purification and properties of the A protein of lactose synthetase. J. Biol. Chem., 246, 6666-6675.

TUCKER (H. A.) (1981). - Physiological control of mammary growth, lactogenesis, and lactation. J. Dairy Sci., 64, 1403-1421.

Vakil (J. R.), Chandan (R. C.), Parky (R. M.) and Shahani (K. M.) (1969). Susceptibility of several microorganisms to milk lysozymes. J. Dairy Sci, 52, 1192-1197.

Vandenbroucke (A.), Dolmans (M.), de Vries-Petiau (G. M.) and Leonis (J.) (1976). - Purification of human milk fucosyltransferase. Arch. Int. Physiol. Biochim., 84, 1112-1113.

VISSER (S.) (1981). - Proteolytic enzymes and their action on milk proteins. A review. Neth. Milk Dairy J., 35, 65-88.

Visser (F. M. W.) and DE GRoot-Mostert (A. E. A.) (1977). - Contribution of enzymes from rennet, starter bacteria and milk to proteolysis and flavour development in Gouda cheese. 4. Protein breakdown: a gel electrophoretical study. Neth. Milk Dairy J., 31, 247-264.

Von Fellenberg (R.) und Horber (H.) (1980). - Multiple Proteaseinhibitoren im Kolostrum und im Eutergewebe der Kuh und ihre mögliche funktionelle Bedeutung. Schweiz. Arch. Tierheilk., 122, 159-168.

Wheeler (M. B.), Anderson (G. B.), Munro (C. J.) and Stabenfeldt (G. H.) (1982). Prolactin response in beef cows and heifers suckling one or two calves. J. Reprod. Fert., 64, 243-249.

Whitworth (N.S.) and GrosvenoR (C. E.) (1978). - Transfer of milk prolactin to the plasma of neonatal rats by intestinal absorption. J. Endocrinol., 79, 191-199.

Wright (R. C.) and Tramer (J.) (1953 a). - Reactivation of milk phosphatase following heat treatment. I. J. Dairy Res., 20, 177-188.

Wright (R. C.) and Tramer (J.) (1953 b). - Reactivation of milk phosphatase following heat treatment II. J. Dairy Res., 20, 258-273. 
WRIGHT (R. C.) and Tramer (J.) (1954). - Reactivation of milk phosphatase following heat treatment III. J. Dairy Res., 21, 37-49.

Wright (R. C.) and Tramer (J.) (1956). - Reactivation of milk phosphatase following heat treatmen IV. The influence of certain ions. $\mathrm{Mg}^{2+}$ or $\mathrm{Zn}^{2+}$ or both play a part in reactivation. J. Dairy Res., 23, 248-256.

Wuthrich (S.), Richterich (R.) und Hostettler (H.) (1963). - Untersuchungen über Milchenzyme. I. Enzyme in Kuhmilch und Frauenmilch. Z. Lebensm. Unters. Forsch., 124, 336-348.

Yasumoto (K.), Iwami (K.), Fushiki (T.) and Mitsuda (H.) (1978). - Purification and enzymatic properties of $\gamma$-glutamyltransferase from bovine colostrum. J. Biochem. (Tokyo), 84, 1227-1236.

ZiKakis (J. P.), Rzucidlo (S. J.) and Biasotto (N. O.) (1977). - Persistence of bovine milk xanthine oxidase activity after gastric digestion in vivo and in vitro. J. Dairy Sci., 60, 533-541. 